Der Medizinischen Fakultät der Georg-August-Universität Göttingen eingereicht von Prof. Dr. med. W. Wuttke

\title{
Der Effekt der aus Cimicifuga racemosa BNO 1055/C001 extrahierten Saponin- und Restfraktion und deren Subfraktionen auf die Herz- und Skelettmuskulatur der ovariektomierten Ratte
}

\author{
INAUGURAL-DISSERTATION \\ zur Erlangung des Doktorgrades \\ der Medizinischen Fakultät der \\ Georg-August-Universität zu Göttingen
}

vorgelegt von

Nina-Antonia Striebe

aus

Hannover

Göttingen 2014 
Die vorliegende Dissertation ist in dem Zeitraum von März 2011 bis Oktober 2014 an der Universitätsmedizin der Georg-August-Universität Göttingen in der Abteilung der Endokrinologie entstanden.

Dekan:

Prof. Dr. rer. nat. H. K. Kroemer

1. Berichterstatter/in: Priv.- Doz. Dr. med. Dana Seidlová-Wuttke (Betreuerin)

2. Berichterstatter/in: Priv.- Doz. Dr. Jörg Männer (Korreferent)

3. Berichterstatter/in: Prof. Dr. Hans-Ulrich Schildhaus (Drittreferent)

4. Berichterstatter/in: Prof. Dr. Margarete Schön (Promotor-Vertreterin)

Tag der mündlichen Prüfung: $\quad$ Mittwoch den 17.06.2015 


\section{Inhaltsverzeichnis}

Abkürzungsverzeichnis

Einleitung 1

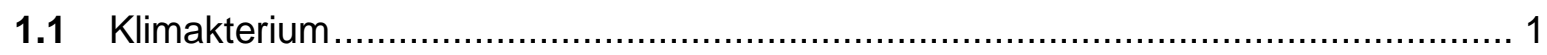

1.1.1 Klimakterium der Frau ...................................................................... 1

1.1.2 Ovariektomierte (ovx) Ratte im Tiermodell ................................................ 2

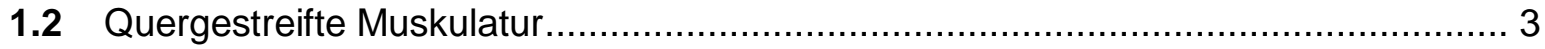

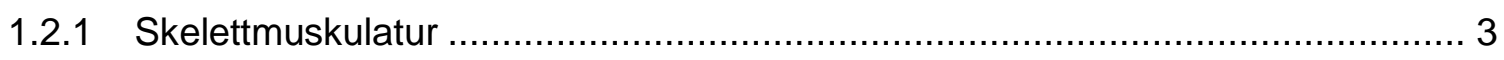

1.2.1.1 Aufbau und Funktion der menschlichen Skelettmuskulatur ....................... 3

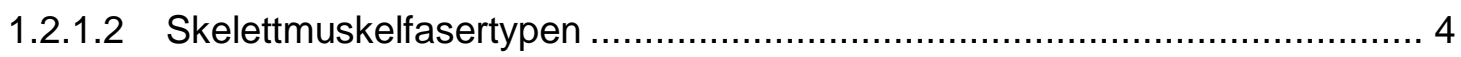

1.2.1.3 Extrazelluläre Matrix (EZM) der Skelettmuskulatur ................................... 5

1.2.1.4 Stoffwechsel der Skelettmuskulatur.................................................... 6

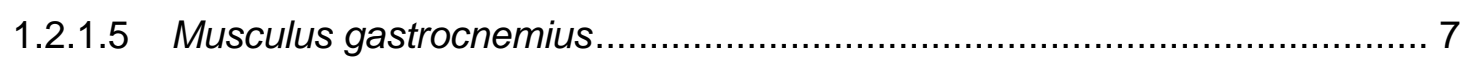

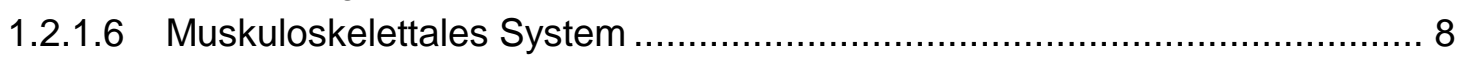

1.2.1.7 Skelettmuskulatur im Klimakterium: Sarkopenie .................................... 9

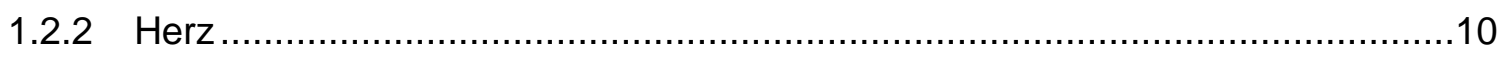

1.2.2.1 Aufbau und Funktion des Herzens ...................................................... 10

1.2.2.2 Kardiomyozyten ........................................................................... 11

1.2.2.3 EZM des Herzens ....................................................................... 11

1.1.2.4 Herz im Klimakterium .................................................................... 12

1.1.2.5 Apex....................................................................................... 13

1.1.2.6 Vergleich von Herz und Skelettmuskulatur .........................................13

1.3 Bisherige Therapieansätze zur Besserung klimakterischer Beschwerden der Frau .14

1.4 Testsubstanz: Cimicifuga racemosa ...........................................................15

1.5 Relevanz und Zielsetzung der Dissertation ............................................... 18

2 Material und Methoden.......................................................................................19

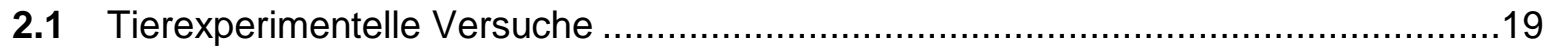

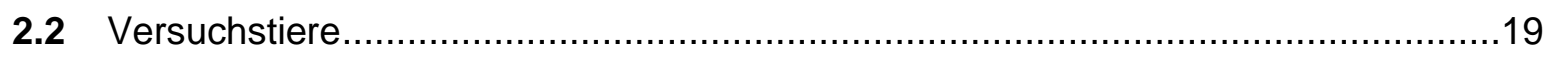

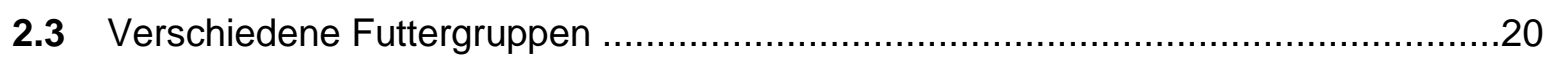

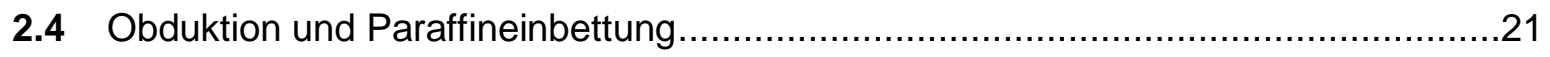

2.5 Herstellung der lichtmikroskopischen Präparate ..............................................22

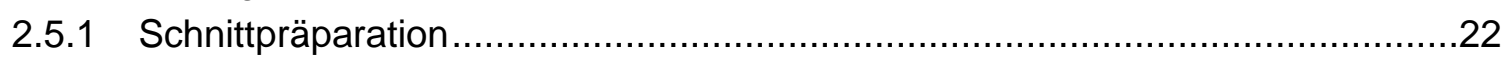

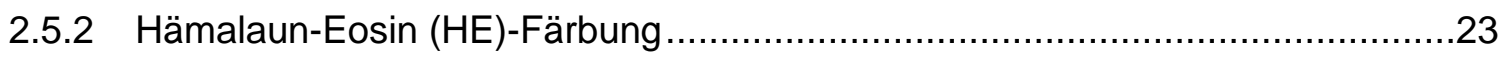

2.5.3 Elastika-Färbung nach Weigert in Kombination mit der Van-Gieson-Färbung ...23

2.6 Auswertung der gefärbten histologischen Präparate .........................................23

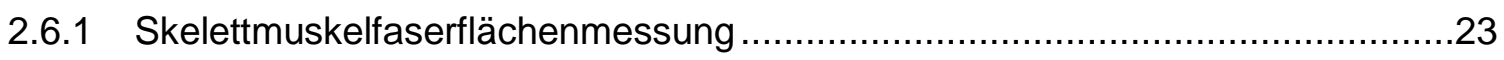

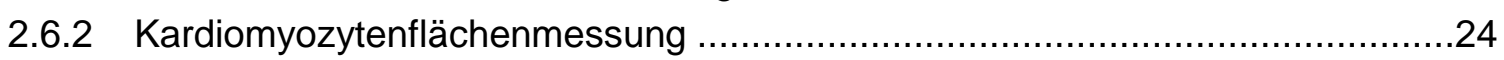

2.6.3 Bestimmung der elastischen Anteile in der Skelettmuskulatur..........................25 
2.6.4 Bestimmung der elastischen Anteile in der Herzmuskulatur ...........................26

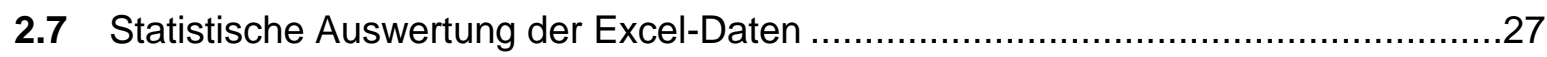

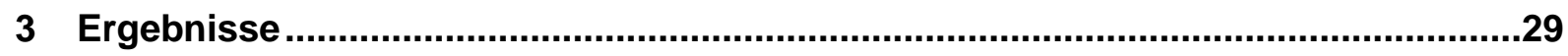

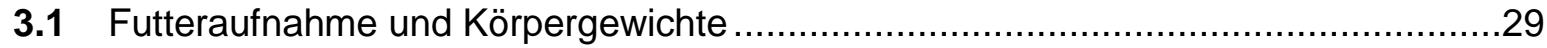

3.2 Ergebnisse der Myozytenflächenmessungen von Skelett- und Herzmuskulatur........32

3.2.1 Ergebnisse der Skelettmuskelfaserflächenmessung ....................................

3.2.2 Ergebnisse der Kardiomyozytenflächenmessung ............................................34

3.3 Bestimmung der elastischen Anteile in Skelett- und Herzmuskulatur ......................36

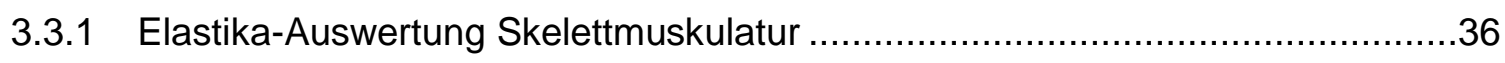

3.3.2 Elastika-Auswertung Herzmuskulatur ......................................................

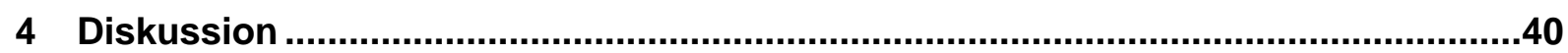

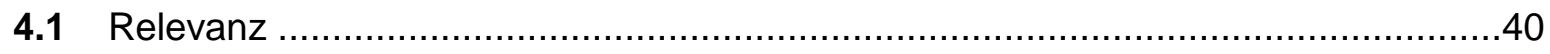

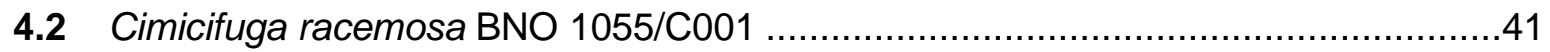

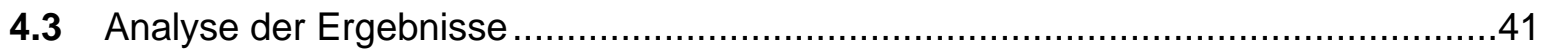

4.3.1 Futteraufnahme der Versuchstiere ..........................................................4

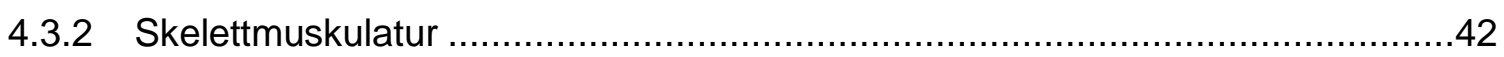

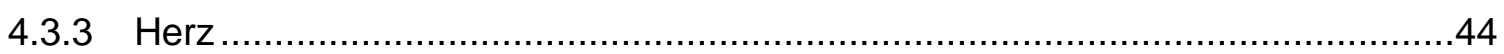

4.3.4 Vergleich von Herz- und Skelettmuskulatur..............................................46

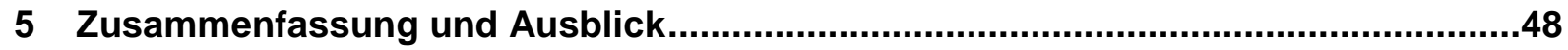

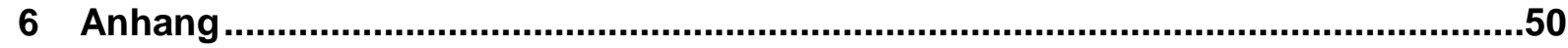

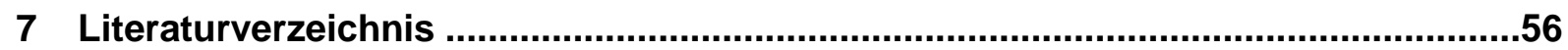

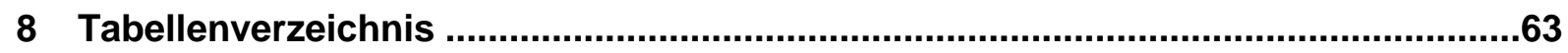

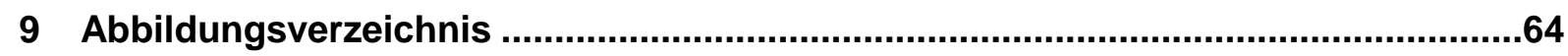

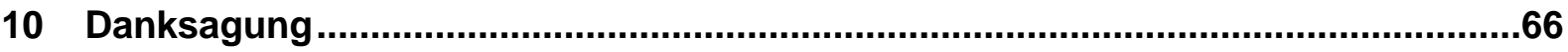

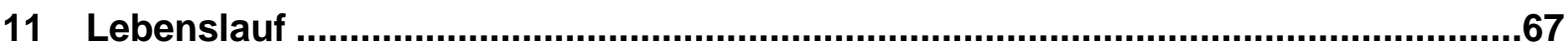




\section{Abkürzungsverzeichnis}

\begin{tabular}{|c|c|}
\hline Abb. & Abbildung \\
\hline Adpt. & Adaptation \\
\hline bzw. & beziehungsweise \\
\hline$C R$ & Cimicifuga racemosa-Extrakt \\
\hline EB & Estradiolbenzoat \\
\hline $\mathrm{ER} \alpha$ & Estrogen receptor $\alpha$ \\
\hline $\mathrm{ER} \beta$ & Estrogen receptor $\beta$ \\
\hline EZM & extrazelluläre Matrix \\
\hline$g$ & Gramm \\
\hline GABA & Gammaaminobuttersäure \\
\hline GAG & Glykosaminoglykane \\
\hline Gw & Gewicht \\
\hline$H E$ & Hämalaun/Hämatoxylin.Eosin \\
\hline$H R T$ & hormone replacement therapy \\
\hline Ko & Kontrollgruppe \\
\hline Mark. & Markierung \\
\hline MTA & Medizinisch technische/r Assistent/in \\
\hline Ovx & Ovariektomie \\
\hline ovx & ovariektomiert \\
\hline$P G$ & Proteoglykane \\
\hline qCT & quantitative Computertomographie \\
\hline Rest & Restfraktion \\
\hline $\mathrm{R} 1$ & Subfraktion 1 der Restfraktion \\
\hline $\mathrm{R} 2$ & Subfraktion 2 der Restfraktion \\
\hline R3 & Subfraktion 3 der Restfraktion \\
\hline Sap & Saponinfraktion \\
\hline S1 & Subfraktion 1 der Saponinfraktion \\
\hline S2 & Subfraktion 1 der Saponinfraktion \\
\hline S3 & Subfraktion 1 der Saponinfraktion \\
\hline SERM & selective estrogen receptor modulator \\
\hline Tab. & Tabelle \\
\hline
\end{tabular}




\section{Einleitung}

Der demographische Wandel bewirkt einen kontinuierlichen Anstieg des Anteils postmenopausaler Frauen an der Weltbevölkerung. Ihr Anteil an der europäischen Gesamtbevölkerung stieg zwischen 1990 und 2010 sukzessiv von 16 auf $20 \%$ (Kuhl 2006). Derzeit befindet sich nahezu jede 3. Frau in oder nach den Wechseljahren (Rossmanith 1998). Das Klimakterium ist für die Frau eine einschneidende, bedeutsame Lebensphase, die mit den für diese Phase typischen Beschwerden und Erkrankungen einhergeht. Nahezu alle Organe unterliegen dem Einfluss des Klimakteriums.

Seit Beginn des 21. Jahrhunderts werden hinsichtlich der klinischen Wirksamkeit und der Sicherheit der Hormonersatztherapie vermehrt Bedenken erhoben, die auf drei großen internationalen Studien der Heart and Estrogen/progestin Replacement Study (HERS) (Grady et al. 1998), der Women's Health Initiative Memory Study (WHI-Study) (Shumaker et al. 2003) und der One Million Women Study (MWS) (Beral et al. 2003) beruhen. Daher stehen nun alternative Therapieansätze verstärkt im Mittelpunkt der Forschung (Rabe et al. 2004). In unterschiedlichen Forschungsprojekten hat sich hierbei $C R$ als effektives, in der klinischen Praxis anwendbares Medikament gezeigt (Osmers et al. 2005). Die Wirkung unserer Testsubstanz Cimicifuga racemosa auf die klimakterisch bedingten Veränderungen bzw. Erkrankungen der quergestreiften Muskulatur und somit der Skelett- und der Herzmuskulatur sind das zentrale Thema dieser Dissertation.

\section{$1.1 \quad$ Klimakterium}

\subsubsection{Klimakterium der Frau}

Das Klimakterium ist die Übergangsphase, in der das Ovar seine endokrine und generative Funktion verliert (Kuhl 2006; Rossmanith 1998). Mit einer Dauer von ca. 15 Jahren lässt es sich in die Prä-, Peri- und Postmenopause unterteilen. Das zentrale, die Phasen definierende Ereignis stellt die Menopause, die letzte spontane Menstruation, dar. Zu diesem Zeitpunkt wird die quantitativ erforderliche endometriale Östrogenstimulation zur Induktion einer uterinen Blutung unterschritten (Rossmanith 1998). Dieser Zeitpunkt ist nur retrospektiv zu bestimmen, nachdem ein Jahr keine weitere ovariell gesteuerte uterine Blutung erfolgte (Pschyremble 2007; Rossmanith 1998). Sie stellt für das Leben einer Frau einen unübersehbaren Einschnitt dar, der in den westlichen Ländern als unwiderrufliches Ende der Fertilität oder zumindest als Bestandteil des Alterungsprozesses verstanden wird (Kuhl 2006). Zumeist erfolgt sie zwischen dem 50. und 52. Lebensjahr. Nach dieser 12-monatigen Amenorrhoe befindet sich die Frau definitionsgemäß in der Postmenopause, bis sie ca. 15 
Jahre später ins Senium eintritt. In den Ausprägungsformen der klimakterischen Symptome und Erkrankungen gibt es erhebliche Unterschiede. Durch das allmähliche Sistieren der Follikelreifung mit konsekutiver Corpus-luteum-Insuffizienz und die dadurch zunehmend verminderte ovarielle Produktion an Sexualsteroiden kommt es zum Hypoöstrogenismus (Rossmanith 1998; Würfel 2010). Bei den möglichen Symptomen handelt es sich bei der Mehrheit um östrogenmangelbedingte Beschwerden und Erkrankungen. Da nahezu alle Gewebe Östrogenrezeptoren aufweisen, kann sich kaum ein Gewebe den klimakterisch bedingten hormonellen Veränderungen entziehen (Seidlová-Wuttke et al. 2003). Insgesamt befindet sich der Körper der klimakterischen Frau in einem eher katabolen Zustand aufgrund der starken Aktivitätsminderung des zuvor anabol wirksamen Hormons Östrogen. Es kann unter anderem zu Hitzewallungen, psychonervösen und kognitiven Störungen, Osteoporose, Gelenkerkrankungen, Involution und Atrophie des Genitales und der Mammae, Sarkopenie, Arteriosklerose, Herzerkrankungen sowie Adipositas kommen (Kuhl 2006).

\subsubsection{Ovariektomierte (ovx) Ratte im Tiermodell}

Die ovx Ratte ist heutzutage ein anerkanntes und häufig angewandtes Modell in der Forschung auf dem Gebiet der Endokrinologie (Bellino 2000).

Der Vorteil der Ratte als Versuchstier in diesem Versuch ist im Vergleich zu anderen Tieren (Schweine, Affen, Hunde, Schafe usw.) das relativ schnelle Ansprechen auf hormonelle Veränderungen, wie sie in diesem Versuch mittels Ovariektomie (Ovx) herbeigeführt wurden (Kalu 1991). Dieses liegt im Vergleich zu den anderen zuvor genannten Tieren an einer kürzeren Entwicklungs- und Lebenszeit der Ratte. Somit können experimentelle Versuche an der Ratte in relativ kurzer Zeit durchgeführt werden. Ein weiterer Aspekt der häufigen Wahl der Ratte als Versuchstier besteht in den im Vergleich zu größeren Tieren günstigen Erwerbs- und Haltungskosten.

Aufgrund des kurzen Lebenszyklus der Ratte von durchschnittlich ungefähr 2 Jahren und des zuvor genannten schnellen Ansprechens auf hormonelle Veränderungen lassen sich klimakteriumsähnliche Veränderungen in einem relativ kurzen Zeitraum untersuchen.

Mittels der Ovx werden die Ratten in einen künstlichen hormonellen Zustand versetzt, der dem einer postmenopausalen oder ovx Frau gleichzusetzen ist. Der physiologische Lebensablauf der femininen Ratte hingegen weist kein Klimakterium auf. Physiologischerweise erreicht die Ratte etwa im 3. Monat ihre vollständige Reife und wird etwa ab dem 15. Lebensmonat hyperestrin. Sie erreicht eine Lebensdauer von ungefähr 18 Monaten (Krinke 2000). 


\section{$1.2 \quad$ Quergestreifte Muskulatur}

Die quergestreifte Muskulatur bildet zwei zum Leben unverzichtbare Organe des Menschens. Die Skelettmuskulatur bildet hierbei das größte Organsystem des menschlichen Körpers. Sie ermöglicht uns, durch Stützmotorik der Gravitation entgegenzuwirken und durch Zielmotorik gerichtete mechanische Bewegungs- und Haltearbeit zu leisten (Speckmann et al. 2008; Hoppele und Billeter 2003). Praktisch alle Ausdrucksformen des Menschen wie Bewegung, Sprache, Mimik, Gestik und auch künstlerische Ausdrucksformen wie Musik und Kunst lassen sich auf die Bewegungen der Skelettmuskulatur zurückführen (Markworth 2005).

Ebenso findet sich quergestreifte Muskulatur im Herz als Teil des Herz-Kreislauf-Systems, das die verschiedenen Organe des Körpers situationsgerecht ver- und entsorgt und somit den Stoffwechselbedarf jeder einzelnen Zelle deckt (Speckmann et al. 2008). Ein Körper ohne diesen Motor unseres Kreislaufes macht das Leben unmöglich. Kardiovaskuläre Erkrankungen bzw. deren Folgen sind derzeit als führende Todesursachen in Deutschland zu betrachten (Erdmann et al. 2008).

Die quergestreifte Muskulatur besitzt ihren Namen aufgrund der elektronenmikroskopisch sichtbaren Streifung mit hellen und dunklen Banden, die auf der strukturellen Anordnung der kontraktilen Filamente beruht.

Diese Herz- und Skelettmuskulatur werden der glatten Muskulatur, die ein wichtiger Bestandteil aller inneren Organe ist, gegenübergestellt (Speckmann et al. 2008).

\subsubsection{Skelettmuskulatur}

\subsubsection{Aufbau und Funktion der menschlichen Skelettmuskulatur}

Die Skelettmuskulatur setzt sich aus ca. 220 einzelnen Skelettmuskeln zusammen. Diese bestehen aus Muskelfaserbündeln unterschiedlicher Anzahl (Schünke et al. 2007). Das Caput mediale des menschlichen Musculus gastrocnemius, unseres Versuchsmuskels, besitzt beim Menschen beispielsweise ca. 579 motorische Einheiten mit jeweils ca. 1934 Muskelfasern pro Einheit, woraus sich eine Gesamtzahl von ca. 1.119.786 Muskelfasern ergibt (Feinstein et al. 1955). Eine Muskelfaser entspricht einer Muskelzelle und bildet die funktionelle Einheit des Muskels. Sie weist eine zylindrische Gestalt mit rundem bis ovalen Querschnitt auf. Je nach Muskel kann sie beim Menschen bis zu $20 \mathrm{~cm}$ lang sein und zwischen 40 - $100 \mu \mathrm{m}$ im Querschnitt gemessen werden. Eine Muskelzelle besitzt ca. 50 membranständige longitudinal ausgerichtete Zellkerne pro mm Muskelfaserstrecke. Ihre Entstehung basiert auf der Fusion vieler einkerniger Myoblasten. Sie setzt sich aus hunderten Myofibrillen zusammen. Diese bestehen aus den regelmäßig angeordneten kontraktilen Myofilamenten Aktin und Myosin, den Regulatorproteinen Troponin und 
Tropomyosin und den Strukturproteinen $\alpha$-Aktinin, Desmin, Nebulin, Titin und Dystrophin (Speckmann et al. 2008; Lüllmann-Rauch 2006; Hoppeler und Billeter 2003; Schünke 2008). Wie zuvor beschrieben, kann der Mensch mittels der Skelettmuskulatur mit der Umgebung v.a. durch Bewegung, Sprache und Mimik interagieren (Markworth 2005; Hoppele und Billeter 2003). Die Aufgabe und Funktion der Skelettmuskulatur sind die zeitlich und situativ adäquate Kontraktion und Relaxation der unterschiedlichen Skelettmuskeln bzw. Muskelgruppen. Im Gegensatz zur quergestreiften Muskulatur des Herzens und der glatten Muskulatur ist sie willkürlich steuerbar. Die Kontraktion beruht auf der Interaktion zwischen Aktin und Myosin in den Sarkomeren. Die Wichtigkeit der Skelettmuskulatur für das muskuloskelettale System auch im Hinblick auf die Entwicklung einer Osteoporose wird im Kapitel 1.2.1.6 besprochen.

Die Skelettmuskulatur der Ratte gilt als etabliertes Modell, da man die menschliche Skelettmuskulatur mit der der Ratte gleichsetzen kann (Krinke 2000).

In dieser Dissertation wird die Skelettmuskulatur durch den Musculus gastrocnemius repräsentiert, welcher im Kapitel 1.2.1.5 abgehandelt wird.

\subsubsection{Skelettmuskelfasertypen}

Angepasst an die spezifischen Anforderungen gibt es drei verschiedene Arten von Muskelfasern. Die Gruppe-I-, -Ila- und -Ilx-Fasern. Die Gruppe-I-Fasern zeigen einen langsamen Kraftanstieg und eine geringe, jedoch lang anhaltende Kontraktionskraft, die durch ihren stark aeroben Stoffwechsel ermöglicht wird. Die Gruppe-Ila-Fasern besitzen einen kombinierten aeroben und anaeroben Stoffwechsel, mit dem sie eine mittelstarke langanhaltende Kontraktionskraft bei sehr schnellem Kraftanstieg hervorrufen können. Die Gruppe-Ilx-Fasern weisen eine hohe, jedoch kurz anhaltende Kontraktionskraft bei schnellem Kraftanstieg aufgrund ihres vorwiegend anaeroben Stoffwechsels auf. Typ-IIxFasern verkürzen sich etwa 10-mal und Typ-Ila-Fasern etwa 3- bis 5-mal schneller als Typ-IFasern (Saltin und Helge 2000).

Abhängig von der Bewegung und der benötigten Kontraktionskraft werden die motorischen Einheiten der verschiedenen Muskelfasertypen vom ZNS aktiviert.

Somit hat der Sprinter ca. <80\% Gruppe-II-Fasern und der Radprofi ca. >80 \% Gruppe-IFasern (Hoppeler und Billeter 2003).

Die spezifischen Sportarten sind jedoch nicht ganz für die Zusammensetzung der Muskelfasertypen in den Muskeln verantwortlich. Es wird angenommen, dass die Anteile der verschiedenen Muskelfasertypen einer genetischen Determination unterliegen und zudem die Innervation des motorischen Nervensystems einen Einfluss auf die Art der Skelettmuskelfaser hat. Das Verhältnis zwischen schnellen und langsamen Muskelfasern in den unterschiedlichen Muskeln richtet sich demzufolge nach der Funktion und Lokalisation 
des Muskels, dem Gebrauch des Muskels und der Genetik des jeweiligen Lebewesens. Jedoch besitzt der Mensch keinen Muskel, in dem nur ein Typ an Skelettmuskelfasern vorkommt. Der Musculus gastrocnemius, unser Versuchsmuskel, besitzt aufgrund seiner zielmotorischen Aktivität beim Laufen und Springen einen höheren Anteil an schnell kontrahierenden Muskelfasern (Markworth 2005). Die Skelettmuskelfasertypen der Ratte und des Menschen gleichen einander (Krinke 2000).

\subsubsection{Extrazelluläre Matrix (EZM) der Skelettmuskulatur}

Die EZM bildet die verschiedenen Bindegewebsanteile der Skelettmuskulatur. Die Skelettmuskeln sind außen von einer Faszie aus straffem Bindegewebe umgeben, auf die nach innen eine lockere Bindegewebsschicht, das Epimysium, folgt. Das sich anschließende Perimysium wird von den Bindegewebssepten gebildet, die den Muskel in Sekundär- und Primärbündel unterteilen. Es bietet den in ihm verlaufenden Nerven und Gefäßen mechanische Unterstützung (Kjaer 2004). Zudem dient es durch seine longitudinale Verbindung mit den Sehnen der Zugkraftübertragung. Aus dem Perimysium entspringt das Endomysium, das jede einzelne Muskelfaser mit retikulären Fasern umgibt, die dem Muskel Reißfestigkeit verleihen (Lüllmann-Rauch 2006). Die EZM verbindet somit verschiedene Gewebe des Körpers miteinander und spielt eine wichtige Rolle für die Kraftübertragung und Struktur in und zwischen Sehnen, Ligamenten, Knochen und Muskeln. Die Kraftübertragung ist von der Integrität der einzelnen Muskelfaser und der EZM abhängig (Kjaer 2004). Die Kraftübertragung des Muskel-Sehnenkomplexes ist von der Interaktion der EZM mit den einzelnen Muskelfasern abhängig (Bailey et al. 1979). Als dynamisches Gewebe reguliert die EZM durch Interaktion zwischen extrazellulären Molekülen, Wachstumsfaktoren und ZellEZM-Signalwegen das Zellverhalten (Velleman 1999). Die EZM passt sich an die Aktivität des jeweiligen Gewebes an (Kjaer 2004).

Die EZM ist definiert als alle im extrazellulären Raum befindlichen, sich durch Interaktion immobilisierenden Makromoleküle. Sie setzt sich aus Kollagenfasern und elastischen Fasern, Glykosaminoglykanen (GAG), Proteoglykanen (PG) und Adhäsionsproteinen zusammen (Lüllmann-Rauch 2006).

Die Formation des Kollagens, das den Hauptbestandteil der EZM darstellt, ist für die Stabilisation und somit die Funktion der Muskulatur ausschlaggebend und essentiell (McCormick 1999; Kjaer 2004). Die hohe mechanische Belastbarkeit der EZM basiert auf der Anordnung des Kollagens und des Elastins, das über sogenanntes crosslinking ein dreidimensionales Netzwerk in der Muskulatur bildet (Kjaer 2004; Reiser et al. 1992). Die aus einem Bündel parallel angeordneter Kollagenfibrillen bestehenden Kollagenfasern sind aufgrund ihrer Zugfestigkeit nicht dehnbar. Ihre Zugfestigkeit basiert auf den stabilen chemisch kovalenten Querbrücken zwischen den Kollagenmolekülen, aus denen sich die 
Kollagenfibrillen zusammensetzen. Kollagene sind stabförmige Proteinmoleküle, die von Fibroblasten sezerniert werden (Lüllmann-Rauch 2006; Laurent et al. 1985). Von den mindestens 27 existierenden Kollagentypen sind die Typen I,II,III,V und XI zur Fibrillenbildung fähig. Die EZM der Skelettmuskulatur besteht hauptsächlich aus den Typen I und III und weist geringe Mengen an Typ IV und V auf (McCormick 1999; Kjaer 2004). Die Kollagene I und III des Epi-, Peri- und Endomysiums sind maßgeblich für die Architektur des Muskels und schützen inn vor Überdehnung (McCormick 1999; Velleman 1999). Intramuskulär und somit im Endo- und Perimysium dominiert signifikant Kollagen Typ I (Kjaer 2004).

Bei welligem und schräg überkreuzendem Verlauf besitzen Kollagenfasern jedoch bis zur Streckung und Parallelausrichtung eine Dehnungsreserve. Ihr Durchmesser beträgt $20 \mu \mathrm{m}$ im Gegensatz zu den weniger als $1 \mu \mathrm{m}$ starken retikulären Fasern, die aus einem Bündel dünner Kollagenfibrillen bestehen. Die retikulären Fasern bilden aufgrund ihrer netzartigen Anordnung ein Stützkorsett mit begrenzter Dehnbarkeit um die einzelnen Muskelfasern. Neben dem Kollagen ist das Elastin das zweite fibrilläre Protein der EZM.

Die meist in Gegenwart der Kollagenfasern anzutreffenden elastischen Fasern lassen sich schon bei geringen Zugkräften elastisch dehnen und verzweigen sich netzartig. Durch ihre Quervernetzung mit den Kollagenfasern sorgen sie für deren Rückführung in den Ruhezustand der welligen Konfiguration. Dagegen verhindern die zugfesten Kollagenfasern eine Überdehnung der elastischen Fasern. Die Bestandteile der elastischen Fasern sind das amorphe Elastin, welches von Mikrofibrillen aus Fibrillin und zahlreichen Proteinen, darunter auch den Fibulinen begleitet wird. Das unlösliche Elastin entsteht infolge spontaner Zusammenlagerung mittels kovalenter Bindungen löslicher Tropoelastin-Moleküle, die von Fibroblasten gebildet werden. Die Fibuline scheinen diesen Prozess zu regulieren. Die Möglichkeit der reversiblen Dehnbarkeit des Elastins liegt nach bisherigen Erkenntnissen in dem Wechsel zwischen einer höheren Ordnung und dessen Rückgang in den Entspannungszustand begründet.

Die Räume zwischen den Fasern sind mit GAG, PG, Adhäsionsproteinen und dem mittels der GAG gebundenen Wasser gefüllt (Lüllmann-Rauch 2006).

\subsubsection{Stoffwechsel der Skelettmuskulatur}

Die Skelettmuskulatur ist ein dynamisches Gewebe, das ständigen Auf- und Abbauprozessen unterliegt. Dieser Prozess wird durch zahlreiche Faktoren beeinflusst und ist im Gegensatz zu Umbauprozessen anderer Gewebe als langsam einzustufen. Der Skelettmuskel unterliegt der körperlichen Aktivität, passt sich an die bestehende Belastung an und kann so seine Leistungsfähigkeit regulieren. Auf das Trainieren eines Muskels bzw. einer Muskelgruppe folgt eine Hypertrophie der Muskelfasern in der belasteten Muskulatur. 
Die Hypertrophie wird durch die Querschnittsvergrößerung der kontraktilen Eiweißfäden in den Myofibrillen und deren anzahlmäßige Zunahme in den Muskelfasern hervorgerufen (Hoppele und Billeter 2003; Speckmann et al. 2008). Die Vermehrung der Myofibrillen führt somit zur Hypertrophie der Muskelfasern. Die hypertrophierten Muskelfasern benötigen zusätzliche Zellkerne, die sie durch Fusion mit den Satellitenzellen erhalten (Osses und Brandan 2001). Die der Basalmembran eng anliegenden Satellitenzellen sind als Zellvorrat anzusehen, aus dem die nicht mehr teilungsfähigen reifen Muskelzellen während einer anabolen Phase Zellkerne beziehen können. Die Anzahl der Satellitenzellen verhält sich proportional zur Aktivität des jeweiligen Muskels. Führt ein Muskel viele und häufige Kontraktionen durch, kommt es zur Hypertrophie und zur Zunahme der Anzahl an Satellitenzellen. Bei Inaktivität eines Muskels atrophiert dieser und die Anzahl an Satellitenzellen sinkt. Auch bei der Regeneration kleinerer geschädigter Bereiche der Muskelfaser - ohne Unterbrechung der Basalmembran - werden die Satellitenzellen zur Proliferation angeregt, um dieses Gewebe mittels Fusion mit den noch bestehenden Muskelfasern auszufüllen (Lüllmann-Rauch 2006). Der Muskel kann umso mehr Arbeit in Form von Kraft leisten, je größer der Querschnitt der einzelnen Muskelfasern ist. Die Muskelschwäche des Alters beruht auf einer Hypotrophie und somit der Verkleinerung der Querschnittsfläche der einzelnen Muskelfasern (Saltin und Helge 2000). In verschiedenen Studien konnte gezeigt werden, dass eine postnatale als auch trainingsbedingte Zunahme der Muskelmasse hauptsächlich auf dem Prinzip der Hypertrophie basiert.

Abgesehen vom durch Training bedingten Auf- und Abbau der Skelettmuskulatur unterliegt dieser Prozess zahlreichen weiteren Faktoren wie den Hormonen, den Wachstumsfaktoren, dem Alter, der Ernährung und der genetischen Veranlagung (Saltin und Helge 2000). Neben einer proteinreichen Ernährung als wichtigem beeinflussenden bzw. limitierenden Faktor sind erwiesene muskelanabole Substanzen unter anderem die Sexualhormone der Gruppe der Steroidhormone, Hormone wie Insulin und Somatotropin, die Somatomedine und die $\beta$ Agonisten. Während diese verschiedenen Faktoren Einfluss auf den Skelettmuskelfaserquerschnitt haben, bleibt jedoch die Skelettmuskelfaseranzahl konstant (Stickland et al. 1975). Der genaue Wirkmechanismus der vorstehend benannten Faktoren auf den Muskelaufbau ist noch nicht bekannt, insbesondere, ob dieser Prozess dem belastungsinduzierten Muskelaufbau gleicht.

\subsubsection{Musculus gastrocnemius}

Der Musculus gastrocnemius hat sich in zahlreichen vorherigen Versuchen dieser und anderen Abteilungen, als gut zu untersuchender Muskel etabliert. Bei den Knochen hat die sich in der Nähe befindliche Tibia für die nach Ovx eintretende Osteoporose als 
Untersuchungsknochen durchgesetzt hat, da sie am stärksten den postovx Knochenschwund zeigt.

Der Musculus gastrocnemius, der aus dem Caput laterale und mediale besteht, bildet zusammen mit dem Musculus soleus den Musculus triceps surae. Er verleiht der Wade ihre typische Form. Der zweiköpfige Wadenmuskel ist für die Plantarflexion und Supination im Fußgelenk und für die Flexion im Kniegelenk verantwortlich. Aufgrund seiner Hauptfunktion des Beugens im Fußgelenk besitzt er eine entscheidende Funktion beim Gehen, Laufen und Springen. Der Musculus soleus erbringt ca. 90 \% der Beugeleistung im oberen Sprunggelenk und ca. $60 \%$ der Supination. Er ist somit der stärkste Flexor im oberen Sprunggelenk und der stärkste Supinator im unteren Sprunggelenk. Mittels seines großflächigen Querschnitts ist er fähig, eine maximale Zugkraft von $300 \mathrm{~kg}$ zu bewirken. Er hebt den Rückfuß des Standbeins beim Gehen und Laufen vom Boden ab und verhindert ein Überkippen nach vorne im oberen Sprunggelenk. Zudem sichert er einen aufrechten Stand (Aumüller et al. 2007).

Der Musculus gastrocnemius ist bei Standardbewegungsabläufen der Ratte und auch des Menschen nahezu permanent aktiv und gut zu präparieren.

Aufgrund der zu Beginn genannten Funktion und der eben genannten Fakten erscheint er als zu untersuchender Skelettmuskel bei der Fragestellung dieser Arbeit prädestiniert.

\subsubsection{Muskuloskelettales System}

Die menschliche Skelettmuskulatur erlangt erst im Zusammenspiel mit Sehnenapparat und Skelettsystem ihre volle Funktionstüchtigkeit. Die Muskulatur und der Knochen stehen dabei in einem engen wechselseitigen Abhängigkeitsverhältnis zueinander. Sie bilden die muskuloskelettale Einheit. Der Knochen stützt die Muskulatur und dient ihr als Ursprungs- und Ansatzstelle. Die Muskulatur wiederum schützt, stabilisiert und stimuliert den Knochen mechanisch (Speckmann et al. 2008). Die Kraftübertragung der kontrahierenden Muskeln auf den Knochen erfolgt über die EZM, die Sehnen und den Bandapparat.

Der Knochen als passiver Stützapparat ist ohne die Muskulatur als aktivem Bewegungsapparat funktionslos. Zusammen mit dem PNS und ZNS, die die Skelettmuskulatur steuern, bilden diese drei Organe das motorische System.

Da durch zahlreiche Versuche gute Ergebnisse von $C R$ auf die postmenopausale Osteoporose detektiert wurden, ist es interessant, die Wirkung dieser Substanz auch auf den Muskel genauer zu untersuchen, da Wechselwirkungen zwischen Muskulatur und Skelett bestehen. Zudem konnte in einigen Studien eine Korrelation und Interaktion zwischen postmenopausaler Sarkopenie und Osteoporose nachgewiesen werden (Sirola und Kröger 2011; Walsh et al. 2006). Die Prävalenz der Sarkopenie ist unter osteoporotischen Frauen signifikant höher als unter Frauen mit normaler Knochendichte (Walsh et al. 2006). Eine 
Sarkopenie, wenig körperliche Betätigung und eine verminderte Knochendichte sind die größten Risikofaktoren für eine Knochenfraktur (Rikkonen et al. 2012).

\subsubsection{Skelettmuskulatur im Klimakterium: Sarkopenie}

Die menopausal bedingte Abnahme der Östrogene führt im Bewegungsapparat u.a. zum Anstieg des Fettgewebsanteils, zur Verminderung der Knochendichte und Verringerung der Muskelmasse und -stärke, der Sarkopenie (Maltais et al. 2009). 1989 lenkte Rosenberg erneut die Aufmerksamkeit auf das Phänomen des postmenopausalen Muskelschwundes und gab inm den Namen Sarkopenie, der sich aus den griechischen Begriffen sarx Fleisch und penia Verlust zusammensetzt (Baumgartner et al.1998; Lang et al. 2010). Sie besteht in einer Abnahme der Muskelmasse bei gleichzeitiger Zunahme der Fettmasse. Sarkopenie ist definiert als zwei Standardabweichungen von der mittleren Muskelmasse gesunder junger Erwachsener als Referenzgruppe. Die Sarkopenie beruht auf einem Missverhältnis zwischen Muskelproteinauf- und -abbau (Maltais et al. 2009; Sirola und Kröger 2011). In zahlreichen Studien konnte gezeigt werden, dass es vorwiegend zur Atrophie der schnellen Fasern des Typ II kommt (Baumgartner et al. 1998; Brown 2008; Burton und Sumukadas 2010). Bedeutung erlangt die Untersuchung der menopausalen Strukturveränderungen der Muskulatur durch die damit einhergehende Instabilität des gesamten muskuloskelettalen Systems (Maltais et al. 2009). Der Verlust an Muskelmasse kann zusätzlich durch den Alterungsprozess, Erkrankungen oder körperliche Inaktivität beschleunigt werden. Die Ätiologie der Sarkopenie ist also multifaktoriell bedingt. Ebenso begünstigt Mangelernährung die muskuläre Atrophie (Evans 2010; Baumgartner et al.1998). Auch der im Alter verstärkte Abbau von Synapsen und die dadurch verminderte Innervation der motorischen Endplatten durch das Nervensystem spielen eine Rolle (Roubenoff 2001). Abhängig von der Referenzmethode konnte eine Prävalenz der Sarkopenie bei 10 bis $40 \%$ postmenopausaler Frauen gezeigt werden (Sirola und Kröger 2011).

Eine der vielen Ursachen für die Sarkopenie ist die klimakterisch bedingte Abnahme der anabolen Sexualhormone (Sirola und Rikkonen 2005; Brown 2008). Viele Studien konnten eine Korrelation von Muskelstärke und zirkulierendem Östrogen nachweisen (Maltais et al. 2009; Sirola und Kröger 2011). In den Kernen der Muskelzellen sind Östrogenrezeptoren (ER) in Form von ER $\alpha$ und ER $\beta$ zu finden (Maltais et al. 2009; Raloff 1996). Es wird angenommen, dass der anabole Effekt des Östrogens auf den Muskel auf einer Stimulation der $E R \alpha$ - und der insulinlike growth factor I IGF-I-Rezeptoren beruht (Maltais et al. 2009; Raloff 1996; Brown 2008). Interessanterweise konnte mittels einiger Experimente gezeigt werden, dass die Anzahl an Östrogenrezeptoren in Muskelfasern postmenopausaler Frauen signifikant niedriger ist, verglichen mit der ihrer Anzahl in Männern, Kindern und präklimakterischen Frauen (Maltais et al. 2009). 
Schwerwiegend sind die Folgen der Sarkopenie auf das muskuloskelettale System und die allgemeine Gesundheit und Lebensqualität. Sie führt zur Demineralisierung des Knochens, wodurch das Osteoporoserisiko steigt, da durch Schwund an Muskulatur die Stabilisierung sowie der mechanische Stimulus des Knochens vermindert ist. Durch Abnahme der Muskelkraft kommt es zu Gangunsicherheit und Mobilitätseinschränkung, in der Folge zu einem erhöhten Sturzrisiko. Sowohl durch die Knochendemineralisierung als auch durch die Abnahme der Muskelkraft resultiert ein erhöhtes Frakturrisiko. Die durch die reduzierte stoffwechselaktive Körpermasse bedingte Aufnahme von Nahrung begünstigt eine Mangelernährung.

Die vorstehend beschriebenen Veränderungen führen sowohl zu einer verminderten Lebensqualität und einem erhöhten Morbiditäts- als auch Mortalitätsrisiko (Möllenhoff et al. 2005; Burton und Sumukadas 2010).

Die derzeitig therapeutisch häufig angewandten und experimentell als sicher wirksam geltenden Maßnahmen beschränken sich auf Muskelkontraktion mittels körperlicher Aktivität, bestehend aus Krafttraining und/oder Vibrationstherapie und proteinreicher Ernährung (Burton und Sumukadas 2010; Taafe 2006). Zudem konnte in einigen Studien gezeigt werden, dass sowohl die Hormontherapie mittels Östrogen, Testosteron oder Wachstumsfaktoren die Substitution von Vitamin D, die Gabe von ACE-Inhibitoren als auch die Einnahme von Kreatin einen anabolen Effekt in der postmenopausalen Muskulatur hervorrufen. Diese kontrovers diskutierten Therapien finden teilweise auch bei anderen postmenopausalen Erkrankungen Anwendung (Burton und Sumukadas 2010).

\subsubsection{Herz}

\subsubsection{Aufbau und Funktion des Herzens}

Das Herz ist als muskuläres Hohlorgan der Motor unseres Körpers. Ohne das Herz wäre der Mensch nicht lebensfähig. Es sorgt als Druck- und Saugpumpe für die Zirkulation des Blutes innerhalb des geschlossenen Blutkreislaufes. Die Pumpwirkung, die sauerstoffarmes Blut in die Lunge und sauerstoffreiches Blut in den Körperkreislauf befördert, beruht auf einem Wechsel von Kontraktion und Erschlaffung der Kardiomyozyten. Als Teil des Herz-KreislaufSystems ist es für die situativ anpasste Ver- und Entsorgung der Organe und aller anderen Gewebe des Körpers zuständig. Es deckt den elementar wichtigen Stoffwechselbedarf jeder einzelnen Zelle. Die Herzmuskulatur ist im Gegensatz zur Skelettmuskulatur nicht willkürlich steuerbar, sondern wird unwillkürlich in erste Linie durch den Sinusknoten gesteuert. Die Erregungsbildung und -leitung folgt einem strengen zeitlichen Muster und garantiert so die reguläre Funktion des Herzens (Speckmann et al. 2008).

Das vom Endokard nach innen und vom Perikard nach außen begrenzte Myokard besteht aus einem linken und rechten Ventrikel mit jeweils vorgeschalteten Vorhöfen. Das 
bindegewebige Herzskelett trennt das Myokard der Ventrikel und Atrien vollständig voneinander. In der Vorhofmuskulatur lässt sich eine oberflächliche von einer tiefen Schicht abgrenzen. Die Ventrikelmuskulatur setzt sich aus vielen sehr komplex angeordneten Kardiomyozyten zusammen. Grundsätzlich lässt sie sich in eine äußere (subepikardiale), mittlere und innere (subendokardiale) Muskelschicht unterteilen. Die subepikardiale Schicht geht an der Spitze der Ventrikel jeweils in einem Wirbel (Vortex cordis) in die tieferen Schichten über (Schünke et al. 2005).

\subsubsection{Kardiomyozyten}

Die Grundbausteine der Herzmuskulatur sind die Kardiomyozyten, die Herzmuskelzellen. Sie weisen beim menschlichen Myokard eine zylindrische Form mit einer Länge von ca. $100 \mu \mathrm{m}$ und einem Durchmesser von $15 \mu \mathrm{m}$ auf. Kardiomyozyten besitzen jedoch im Gegensatz zur Skelettmuskulatur nur einen, gelegentlich zwei im Zentrum gelegene Zellkerne. An ihren Enden sind sie jeweils mit mehreren Nachbarzellen mittels mechanischer Haftkontakte und Kommunikationskontakte, den Gap junctions, miteinander verbunden. Die Erregung der Kardiomyozyten erfolgt nicht wie in die Skelettmuskulatur durch nervale Stimulation. Die Kontraktion wird hier mittels eines herzeigenen Erregungsbildungszentrums generiert und über Erregungsbahnen fortgeleitet (Lüllmann-Rauch 2006).

\subsubsection{EZM des Herzens}

Auch beim Herzen gliedert die bindegewebige EZM, die sich aus Epi-, Peri- und Endomysium zusammensetzt, das Myokard in Bündel (Lüllmann-Rauch 2006). Das Epimysium ist an den endo- und epikardialen Oberflächen des Myokards lokalisiert, wo es die endothelialen und mesothelialen Zellen mechanisch unterstützt. Das Perimysium umgibt jeweils mehrere Muskelfasern und verbindet die verschiedenen Muskelfaserbündel miteinander. Aus inm entspringt das Endomysium, das die einzelnen Kardiomyozyten umgibt und diese ebenfalls miteinander verbindet (Berk et al. 2007). Die EZM des Myokards spielt eine entscheidende Rolle für die Integrität und Funktion des Herzens. Sie bildet aus den einzelnen Myozyten eine strukturelle und funktionelle Einheit. Sie dient den Myozyten und Gefäßen als Stützgerüst. Im Myokard gibt es die 5 verschiedenen Kollagensubtypen Typ I, III, IV, V und VI. Das steife Kollagen vom Typ I, welches $80 \%$ und das elastische Kollagen vom Typ III, das $10 \%$ des myokardialen Gesamtkollagens ausmachen, sind somit wie auch in der Skelettmuskulatur die Hauptkomponenten der EZM (Pauschinger et al. 2002). Typ IKollagene sind relativ dick und steif und dienen vorwiegend der Kraftverteilung und Koordination (Weber et al. 1988). Typ III-Kollagene sind hingegen relativ dünne elastische Fasern (Lapiere et al. 1977). Durch die Mischung an elastischen, steifen und zugfesten 
Fasern kann das Myokard sowohl diastolischen als auch systolischen Funktionen gerecht werden. Die kardialen Fibroblasten sind für die Synthese und Positionierung der Kollagenfasern Typ I und Typ III sowie des Elastins zuständig (Eghbali et al. 1991). Die weiteren Bestandteile der EZM des Myokards gleichen im wesentlichen denen der Skelettmuskulatur und bestehen aus elastischen Fasern, GAG, PG und Adhäsionsproteinen. Verschiedene Faktoren induzieren in den myokardialen Fibroblasten eine Kollagensynthese. U.a. sind hier Zytokine wie das Interleukin $1 \beta$, Wachstumsfaktoren wie der Platelet-Derived Growth Factor PDGF oder der Transforming Growth Factor $\beta$, Aldosteron, Angiotensin und mechanischer Stretch zu nennen. Jedoch sind zahlreiche exakte molekulare Mechanismen der Umgestaltung der EZM bisher noch nicht eindeutig aufgeschlüsselt (Pauschinger et al. 2002). Durch den Einfluss der vorstehend bezeichneten Substanzen kann es zur Umstrukturierung oder Verminderung der EZM durch das sogenannte remodeling kommen. Im Rahmen verschiedener Untersuchungen konnten solche Umbauprozesse als wichtiger Faktor bei der Entwicklung einer Herzinsuffizienz identifiziert werden (Pauschinger et al. 2002). Beim remodeling des Kollagennetzwerkes kann es zu einer systolischen Dysfunktion kommen, da eine strukturelle Änderung der EZM Funktionsänderungen des Myokards zur Folge hat. Das Kollagennetzwerk dient den Kardiomyozyten zur Unterstützung und geometrischen Ausrichtung und der Koordination der Kontraktion. Es ist zudem wichtig für die Interaktion der endomysialen Komponenten wie Kollagen und Laminin mit ihren Rezeptoren, um die Synchronität der Kontraktion zu ermöglichen. Des Weiteren bedingt es das Gleiten der Kardiomyozyten bei der ventrikulären Dilatation (Berk et al. 2007).

\subsubsection{Herz im Klimakterium}

Kardiovaskuläre Erkrankungen sind sowohl bei Männern als auch bei Frauen die häufigste Todesursache. Bei jungen Frauen ist die Inzidenz des Herzinfarktes im Gegensatz zu jungen Männern sehr gering. Nach der Menopause steigt bei den Frauen die Inzidenz des Herzinfarktes rapide an. $14 \%$ der zwischen 45 und 64 Jahren alten Frauen und $33 \%$ der Frauen über 65 leiden an kardiovaskulären Erkrankungen (Kuhl 2006). Das Risiko einer $50-$ jährigen Frau im verbleibenden Leben einen Herzinfarkt zu erleiden, liegt bei $46 \%$, mit einem 31-\%igen Risiko, daran zu sterben. Nach bilateraler Ovx konnte ein signifikant höheres Risiko der Inzidenz von Herz-Kreislauf-Erkrankungen in Abhängigkeit vom Östrogenmangel festgestellt werden (Kuhl 2006). Erhöhter Blutdruck und kardiale Hypertrophie konnten als Folge des Klimakteriums detektiert werden (Jazbutyte et al. 2006). Die Inzidenz der koronaren Herzkrankheit steigt nach der Menopause aufgrund des Östrogendefizits rapide an (Saltikin und Alevizaki 2007; Pelzer et al. 1996). Es ist bekannt, dass die Kardiomyozyten und kardiale Fibroblasten wie die Skelettmuskelfasern die 
Östrogenrezeptoren ER $\alpha$ und ER $\beta$ enthalten, jedoch ist der Wirkungsmechanismus des Östrogens bzw. des klimakterisch bedingten Östrogenmangels aufs Herz noch nicht vollständig geklärt (Xu et al. 2003).

Die altersbedingten und klimakterischen Veränderungen des Herzens sind aufgrund mangelnder Forschungsergebnisse nicht klar voneinander abgrenzbar. Die altersbedingten Veränderungen des Herzens bestehen in einer Hypertrophie des Herzens, bedingt durch eine Zunahme der Kardiomyozytenvolumina, einer verminderten Myozytenzahl, einer geringeren Kapillardichte, einer Zunahme der Typ-I-Kollagenfasern und der Kollagenquervernetzung, vermehrter Amyloid- und Lipofuszineinlagerungen, der Abnahme der Anzahl an Schrittmacherzellen im Sinusknoten und einer gesteigerten Myozytensteifigkeit. Im vaskulären myokardialen System kommt es zudem zur Dickenzunahme der Intima und Media, zum erhöhten Matrix-Kollagengehalt und zur Abnahme des Elastins (Kindermann und Böhm 2011). Das zuvor beschriebene altersbedingte myokardiale remodeling, das eine kardiale Hypertrophie, eine Modifikation der kontraktilen Maschinerie der Kardiomyozyten und auch Alterationen der EZM, die zur Akkumulation von Kollagen führen, zur Folge hat, kann eine ventrikuläre Steifigkeit und Fibrose, elektrische und mechanische Veränderungen und eine Prädisposition von Herzfehlern, Arrhythmien oder plötzlichen Tod bewirken. Verschiedene Studien konnten zeigen, dass diese Erkrankungen bei Frauen postmenopausal ihren Höhepunkt haben (Xu et al. 2003).

\subsubsection{Apex}

Im diesem Versuch wurde das Herz immer quer zur Längsachse des Apex geschnitten, um eine Vergleichbarkeit der verschiedenen Organe zu ermöglichen. Auf diese Art und Weise entstanden in den Schnitten viele quer angeschnittene Kardiomyozyten, die in die Messung einbezogen werden konnten. So wurde stets der Querschnitt der Kardiomyozyten der Herzkammern gemessen, was wiederum für die Vergleichbarkeit der verschiedenen Herzen erforderlich ist.

\subsubsection{Vergleich von Herz und Skelettmuskulatur}

Obwohl beide Organe Teil der quergestreiften Muskulatur sind, so gibt es doch entscheidende Unterschiede in der Gewebestruktur. Die der Willkür unterworfene Skelettmuskulatur ist der durch den vegetativ beeinflussten, primär Sinusknoten gesteuerten Herzmuskulatur gegenüberzustellen.

Die im Vergleich zu den Skelettmuskelfasern kürzeren Kardiomyozyten weisen weniger Mitochondrien und eine geringere ATPase-Funktion auf, sind jedoch im Gegensatz zu den Skelettmuskelzellen tetanisierbar. 
Skelettmuskelfasern besitzen zahlreiche randständige Zellkerne, wohingegen Kardiomyozyten jeweils einen zentralen bis maximal zwei Zellkerne enthalten.

Im Gegensatz zur Skelettmuskulatur besitzt die Herzmuskulatur keine Satellitenzellen zur Regeneration. Abgestorbene Herzmuskulatur kann somit nicht erneuert werden, da Kardiomyozyten terminal differenzierte postmitotische Zellen sind. Abgestorbenes Myokardgewebe wird bei der Regeneration bindegewebig umgewandelt.

Gemeinsame Merkmale der Herz- und Skelettmuskulatur sind sowohl die Querstreifung als auch der gleiche molekulare Mechanismus der Kontraktion und zudem eine ähnliche Zusammensetzung der EZM mit sowohl Kollagen I und III als Hauptbestandteilen.

\subsection{Bisherige Therapieansätze zur Besserung klimakterischer Beschwerden der Frau}

Bereits seit Jahrzehnten steht die Suche nach effizienten nebenwirkungsarmen Therapien klimakterischer Beschwerden im Fokus entsprechender Studien. Nachdem als Ursache die verminderte Ausschüttung von Östrogenen identifiziert werden konnte, zielten die Forschungsarbeiten konsequenterweise auf Möglichkeiten zur kompensatorischen Substitution der Östrogene ab. Östrogene, die als Steroide den Sexualhormonen zuzuordnen sind, werden in verschiedenen Geweben mittels der Aromatase-Reaktion aus Testosteron gebildet. Hauptbildungsort sind die Granulosazellen der Ovarialfollikel. In vernachlässigbaren Mengen werden sie auch in anderen Geweben mit Aromataseaktivität wie der Plazenta, der Nebennierenrinde, dem Muskel-, Fett- und Nervengewebe synthetisiert. Das wirksamste körpereigene Östrogen ist das Östradiol-17ß (Rassow et al. 2008; Zhao et al. 2005). Die klassische $H R T$, die aus einer Östrogen- und Gestagensubstitution besteht, fand in den letzten Jahren, basierend auf unterschiedlichen Studien, zunehmend Ablehnung aufgrund der unvorteilhaften Nutzen-Risiko-Relation (Wuttke et al. 2003; Kuhl et al. 2006). Maßgeblich tragen zu dieser negativen Bewertung die drei großen internationalen Studien der Heart and Estrogen/progestin Replacement Study (HERS), der Women's Health Initiative Study (WHI-Study) und der One Million Women Study (MWS) bei (Rabe et al. 2004).

Unter anderem bereits detektierte Nebenwirkungen der HRT sind ein erhöhtes Risiko, an invasivem Brustkrebs und kardiovaskulären Erkrankungen inklusive der Venenthrombose zu erkranken (Wuttke et al. 2003; Borrelli und Edzard 2002). Die unverminderte Suche nach Alternativen zur HRT ist daher nachvollziehbar (Liske 1998; Wuttke et al. 2003). Neben der Hormonsubstitution, Nahrungsergänzungsmitteln und pflanzlichen therapeutischen Optionen ist unter den Heilpflanzen in den letzten Jahrzehnten unter anderem $C R$ intensiv in den Mittelpunkt der Forschung gerückt. 


\subsection{Testsubstanz: Cimicifuga racemosa}

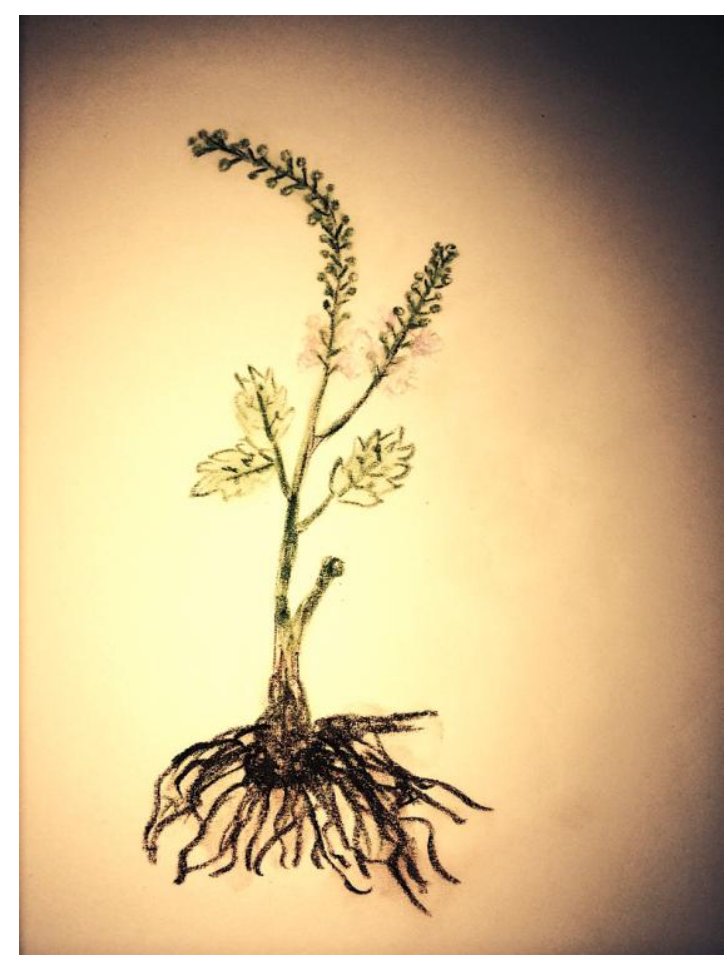

Abb. 1.1 Ansicht der Pflanze $C R$, deren Wurzelstock Verwendung findet (selbstangefertigte Zeichnung)

Cimicifuga racemosa -neben vielen anderen Bezeichnungen- z.B. auch als Traubensilberkerze, Wanzenkraut, Frauenwurzel, Black Cohosh bekannt, gehört zur Gattung Actaea, der Familie der Hahnenfußgewächse (Ranunculaceae). Der lateinische Begriff Cimicifuga leitet sich von lateinisch cimex, Wanze und fuga, Flucht ab. Auch die Bezeichnung Wanzenkraut bezieht sich auf den abstoßenden Geruch der Blüten, der Blattwanzen vertreiben soll. Schon die Siedler hängten die Blüten rechts und links neben den Hauseingang, um so Schädlinge zu vertreiben (Stammel 2000).

Racemosa bedeutet traubenartig und ist auf die Anordnung des Blütenstandes zurückzuführen. Da die Indianer Kanadas, Wisconsins und Missouris CR gegen die Folgen von Schlangenbissen und zur Geburtserleichterung verwendeten, wurde sie umgangssprachlich snakeroot und squawroot genannt.

Es handelt sich um eine aufrecht wachsende, mehrjährige Staude mit großen zwei- bis dreifach gefiederten Blättern und kleinen weißen, in einer Traube oder Rispe angeordneten Blüten. Ihre Blütezeit ist im Juli. Aufgrund ihres schönen Blütenstandes erfreut sie sich großer Beliebtheit als Gartenpflanze. Angesiedelt ist die bis zu 2,50 Meter hohe buschige Staude in dunklen Wäldern, an Waldrändern und Böschungen im Norden der USA und in Kanada. Als Arzneimittel Verwendung findet das nach der Fruchtreife getrocknete Rhizom 
(Wurzelstock). Seit über 30 Jahren wird die Pflanze vermarktet (Boblitz 2002). Derzeit sind mehr als 30 verschiedene Arzneimittel mit Extrakten aus dem Cimicifugawurzelstock erhältlich. Diese Dissertation bezieht sich auf das Produkt Klimadynon der Firma Bionorica, bei dem es sich um den Cimicifugawurzelstock-Spezialtrockenextrakt BNO 1055 handelt. Er ist als Filmtablette mit 2,8 mg Trockenextrakt aus $C R$ vermischt mit anderen Hilfsbestandteilen erhältlich. Genauere Informationen zu Klimadynon sind im Anhang unter 1.A zu finden. Der therapeutische Einsatz des Rhizoms besitzt lange Tradition. Bereits die Indianerstämme und ihre Schamanen und Kolonisten Nordamerikas benutzten $C R$ zur Behandlung von Gelenkschmerzen, Myalgien, Neuralgien, klimakterischen und generellen gynäkologischen Symptomen, Geburtsschmerzen und rheumatischen Beschwerden (Liske 1998; Borrelli und Edzard 2002). In der traditionellen chinesischen Medizin gelangt es antiinflammatorisch, analgetisch und antipyretisch zum Einsatz (Liske 1998). Die therapeutische Wirksamkeit von $C R$ bei der Behandlung von klimakterischen Beschwerden wird von zahlreichen Experten unabhängig voneinander bestätigt, als Resultat hat $C R$ in diesem Zusammenhang seit Ende der 50er Jahre weite Verbreitung erfahren (Osmers et al. 2005). In mehreren Studien bestätigte sich eine gute Verträglichkeit ohne klinisch relevante Nebenwirkungen. Neben zahlreichen vermuteten Wirkungen dieser Pflanze sind einige Effekte experimentell bestätigt und werden therapeutisch genutzt. $C R$ vermindert signifikant klimakterische Hitzewallungen und die Produktion von Nachtschweiß (Wuttke et al. 2006; Seidlová-Wuttke 2003a). Indem es die Aktivität der Osteoblasten erhöht, weist es osteoprotektive Eigenschaften auf und reduziert zudem das paratibiale und intraabdominelle Fettgewebe (Seidlová-Wuttke et al. 2003b). Erste Untersuchungen dieser Forschungsabteilung und auch externe Studien deuten auf eine Wirksamkeit bestimmter Cimicifuga-Zubereitungen auch bei der Vorbeugung und Behandlung von altersbedingten Veränderungen der Prostata hin (Seidlová-Wuttke et al. 2006; Bone und Mills 2013). Es wird die Auffassung vertreten, dass die Substanz ähnlich wie ein Aromatase- bzw. 5-Alpha-Reduktase-Hemmer wirke (Seidlóva-Wuttke et al. 2006). Allerdings sind noch weitere Untersuchungen notwendig um diesen Effekt zu bestätigen.

$C R$ bindet weder an ER $\alpha, E R \beta$ noch an andere Steroidrezeptoren. Somit besitzt es keine Wirkung auf jegliche Östrogenrezeptoren und ist daher kein „Selektiver Östrogen-RezeptorModulator" SERM, wie noch vor einigen Jahren vermutet wurde (Wuttke et al. 2006).

Die Vorteile von $C R$ im Vergleich zur HRT bestehen darin, dass es keine proliferationsfördernde Wirkung auf den Uterus und die Vagina erzeugt (Liske 1998; Seidlová-Wuttke et al. 2003a; Seidlová-Wuttke et al. 2003b) und auch kein erhöhtes Brustkrebsrisiko bewirkt (Liske 1998).

Unter anderem wurden im Rahmen des Projektes „Osteoporoseprophylaxe mit pflanzlichen Wirkstoffen" der bayerischen Forschungsstiftung von der endokrinologischen Forschungsgruppe der Universitätsmedizin Göttingen in den letzten Jahren aus $C R$ die einzelnen 
Subfraktionen extrahiert und nach und nach immer differenzierter die Subsubstanzen der Subfraktionen bestimmt. Die aktuellste Analytik der Zusammensetzung von $C R$, die am 12.04.2011 auf dem 6. Wissenschaftlichen Meeting Cimicifuga -Osteoporose in Würzburg von Herrn M. Kammann vorgestellt wurde und uns von dem Pharmaunternehmen BIONORICA seitdem zur Verfügung gestellt wurde, zeigt die folgende Abb. 1.2.

\section{Cimicifuga TE}

S1 Polare Saponine Actein Deoxyactein Isoferulasäure Spuren: Methylserotonin Cimipronidin; Cyclocimipronidin; Betasiphenol

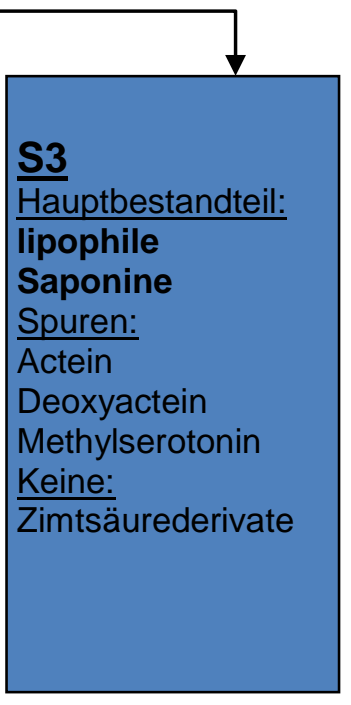

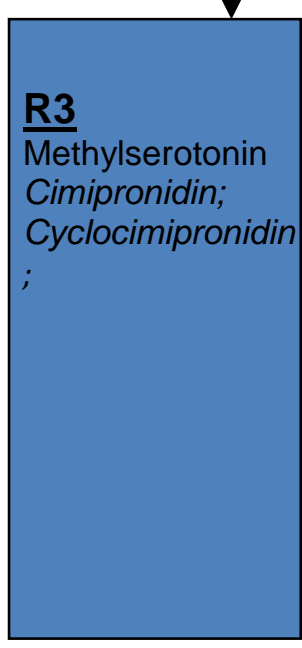

Abb. 1.2 CR Subfraktionen: Komplementierende Analytik zu C001/S/1-2 und C001/R/

1-3: Selbstständig wissenschaftlich erarbeitet und uns bereits seit dem 12.07.2011 von dem Pharmaunternehmen BIONORICA zur Verfügung gestellt. Am 16.01.2013 wurde die Analytik unter der Nummer EP2545932 A1 veröffentlicht.

Wie aus der Abb. 1.2 ersichtlich wird, lässt sich $C R$ in eine Saponinfraktion und eine Restfraktion untergliedern. Diese zwei Fraktionen lassen sich in jeweils drei Subfraktionen unterteilen. Die Saponinfraktion setzt sich aus der S1-, S2- und S3-Subfraktion zusammen. Die Restfraktion lässt sich in die R1-, R2- und R3-Subfraktion gliedern. Die vielen Subsubstanzen der Subfraktionen wurden in zahlreichen Versuchen detektiert. Aus der Abb. geht hervor, dass die Saponinfraktion als Hauptbestandteile die lipophilen Saponine enthält, 
vor allem Deoxyactein und Actein. Die Restfraktion umfasst als Hauptbestandteile eher hydrophile Substanzen wie Methylserotonin, Kaffeesäure und Phenylpropanoide. Auffällig ist, dass jede der sechs Subfraktionen Methylserotonin aufweist. Trotz dieser detaillierten Analyse und der vielen bereits detektierten Wirkungen bleiben noch viele Fragen zu den Wirkungsmechanismen dieser Pflanze bisher unbeantwortet.

\subsection{Relevanz und Zielsetzung der Dissertation}

Das Ziel dieser Dissertation besteht in der Untersuchung der Auswirkung der aus CR extrahierten Fraktionen und deren Subfraktionen auf die Herz- und Skelettmuskulatur der ovx Sprague-Dawley-Ratte. Sie ist Teil des Forschungsprojekts (AZ-838-081.4.200931.3.2012) Osteoporoseprophylaxe mit pflanzlichen Wirkstoffen der bayerischen Forschungsstiftung. In den letzten Jahrzehnten wurde in zahlreichen unterschiedlichen Studien versucht, die Zusammensetzung, Wirkweise und Auswirkung von $C R$ auf verschiedene Organe bei mittels ovx ins Klimakterium versetzten Versuchstieren genauer zu analysieren. Da wie bereits dargestellt vom Klimakterium nahezu kein Gewebe unbeeinträchtigt bleibt, besteht ein generelles Interesse, die ganzheitliche Auswirkung des Extraktes zu erfassen. Sowohl sind unter neuen Versuchsansätzen die Auswirkung auf die bereits besser erforschten Organe wie beispielsweise den Knochen, den Uterus und die Vagina von Interesse als auch auf bisher wenig erforschte Organe wie in diesem Versuch die Herz- und Skelettmuskulatur, um das Wissen über das Wirkungs- und/oder Nebenwirkungsspektrum zu erweitern. In der Versuchsreihe FUTSUB fanden nahezu alle Organe Verwendung. Die vorliegende tierexperimentelle Untersuchung behandelt die Frage, ob die aus $C R$ extrahierten Fraktionen und/oder deren Subfraktionen einen Einfluss auf die Skelettmuskelfaserfläche, die Kardiomyozytenfläche und/oder die EZM/ elastischen Fasern der quergestreiften Muskulatur haben. Durch die genauere Aufspaltung des Gesamtextraktes in Fraktionen und deren Subfraktionen ergibt sich die Möglichkeit, den einzelnen Bestandteilen ihre spezifischen Wirkungen genauer zuzuordnen und diese ggf. in Zukunft therapeutisch gezielter einsetzen zu können. Auch stellt sich die Frage nach den unterschiedlichen Wirkungen der aus $C R$ extrahierten Fraktionen im Vergleich zu den aus innen wiederum extrahierten Subfraktionen. Ein weiterer Aspekt der Dissertation ist die vergleichende Untersuchung der Wirkweise und Auswirkung der aus $C R$ extrahierten Fraktionen und deren Subfraktionen auf die Herz- und Skelettmuskulatur. Im Ergebnis ist von Interesse, ob die jeweilige Auswirkung als positiv oder negativ für die Gesundheit der klimakterischen Frau einzustufen ist. Daraus könnten sich neue Schlüsse für den gezielteren therapeutischen Einsatz von $C R$ und/ oder dessen Fraktionen/ Subfraktionen ziehen lassen. 


\section{Material und Methoden}

\subsection{Tierexperimentelle Versuche}

Die tierexperimentellen Versuche haben vom 25.08. bis zum 04.10.2010 im Universitätsklinikum Göttingen stattgefunden. Die Versuche wurden von der Bezirksregierung Braunschweig (33.11.42504-04-043/08) genehmigt und unter Aufsicht von Priv.-Doz. Dr. med Seidlová-Wuttke durchgeführt. Rahmen für diese Versuche war ein von der Bayerischen Forschungsstiftung finanziertes Projekt : "AZ-838-081.4.2009- 31.3.2012" Osteoporoseprophylaxe mit pflanzlichen Wirkstoffen.(2009-2012) Die nachfolgenden Ergebnisse zum Futterverbrauch und Körpergewicht der Tiere standen allen Doktoranden der Arbeitsgruppe als Datenpool zur Verfügung. An der Durchführung und Auswertung dieser Versuche war ich nicht beteiligt. Meine Labortätigkeit begann im März 2011 mit der Bearbeitung der in Paraffinblöcke eingebetteten Herzen und Mm. gastrocnemii.

\subsection{Versuchstiere}

Es wurden 100 weibliche Sprague-Dawley Ratten (Fa. Harlan-Winkelmann, Borchen) für den Versuch ausgewählt. An den bei Ankunft im Labor etwa drei Monate alten Tieren wurden zunächst per quantitativer Computertomographie (qCT) Knochendichte-Messungen durchgeführt. Im Anschluss wurden die Tiere ovariektomiert (ovx). Im Zuge dieser Operation wurde jedem Tier subkutan in der Nackenregion ein Transponder (Emsikon Jung GmbH, Fastinning) zur Identifikation und Gruppenzuordnung implantiert.

Die 100 Tiere wurden auf 20 Käfige zu je 5 Tieren in unterschiedliche Futtergruppen unterteilt. Die Vergleichbarkeit der 20 Tiergruppen wurde hergestellt, indem die Tiere so auf die Käfige verteilt wurden, dass vergleichbare Gesamtkörpergewichte der verschiedenen Kohorten entstanden. So verfügten die 5 Tiere eines jeden Käfigs über ein etwa gleiches mittleres Körpergewicht (252+/-5g). Das Rattenkollektiv wurde unter standardisierten tierfreundlichen Bedingungen gehalten. Sojafreies Futter (ssniff spezialitäten $\mathrm{GmbH}$, Soest) und Wasser standen den Ratten in der 1-wöchigen Eingewöhnungsphase zur freien Verfügung. Am tierexperimentellen Teil dieses Versuches habe ich nicht teilgenommen.

Zur Veranschaulichung des tierexperimentellen Teils unseres Versuches soll der folgende Zeitstrahl Abb. 2.1 dienen. 


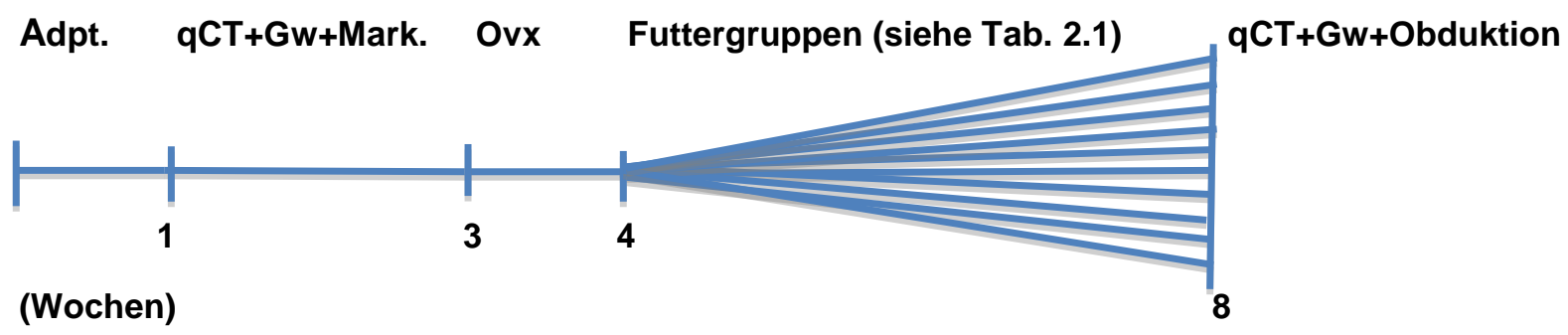

Abb. 2.1 Tierexperimenteller Zeitverlauf: bestehend aus Adaptation, qCT, Gewichtsmessung und Markierung, Ovx und den Strahlen der Futtergruppen, deren Zusammensetzung in Tab. 2.1 dargestellt wird

\subsection{Verschiedene Futtergruppen}

Den Ratten wurden unmittelbar nach der Ovx über einen Zeitraum von 4 Wochen experimentell Futter verteilt. Eine Übersicht über die verschiedenen Gruppen und deren Futterbeimengungen, deren Menge in zahlreichen Versuchen zuvor exakt analysiert wurde, bietet die Tab. 2.1. Das jeweilige Futter als auch Wasser stand den Ratten zur freien Verfügung. Die Tiere wurden unter von der Bezirksstelle Braunschweig vorgegebenen teirexperimentellen Bedingungen wie konstanter Raumtemperatur von $23^{\circ}$ Celsius, einer relativen Luftfeuchtigkeit im Bereich zwischen 50 und $55 \%$ sowie mit Beleuchtung von 6.00 18.00 Uhr gehalten. In Kenntnis einer durchschnittlichen Futteraufnahme der Ratte von 17$18 \mathrm{~g}$ pro Tag und der Menge der diesem Futter beigemengten CR Gesamtsubstanz sowie deren prozentualer Zusammensetzung ließ sich der Anteil jeder einzelnen Fraktion bestimmen. Die Dosis in mg/kg Futter sowie die Futteraufnahme ist in Tab. 2.1 beschrieben. Die Dosis der Subfraktionen entspricht ihrem Anteil an einer bekannten wirksamen Menge CR BNO 1055 Gesamtextrakt von ca. 9 mg/d. Damit wurde sichergestellt, dass jedem Tier durch die jeweilige Subfraktion die gleiche Menge an Inhaltsstoffen zugeführt wurde, wie im Gesamt $C R$ Extrakt vorhanden war. 


\begin{tabular}{|c|c|c|c|}
\hline Futterart & Gruppe & $\begin{array}{c}\text { Anzahl der } \\
\text { Tiere }\end{array}$ & Dosis in mg/kg Futter \\
\hline Ko & Ko & 10 & keine \\
\hline EB & EB & 10 & 10 \\
\hline Saponinfraktion & Sap & 10 & 382,35 \\
\hline Restfraktion & Rest & 10 & 31,2 \\
\hline Subfraktion 1 der Saponinfraktion & S1 & 10 & 46,06 \\
\hline Subfraktion 2 der Saponinfraktion & S2 & 10 & 46,04 \\
\hline Subfraktion 3 der Saponinfraktion & S3 & 10 & 276,81 \\
\hline Subfraktion 1 der Restfraktion & R1 & 10 & 75,37 \\
\hline Subfraktion 2 der Restfraktion & R2 & 10 & 35,979 \\
\hline Subfraktion 3 der Restfraktion & R3 & 10 & 17,6 \\
\hline
\end{tabular}

${ }^{*} \mathrm{p}<0,05$ vs Ko

\section{Tab. 2.1 Verschiedene Futtergruppen mit berechneten Futterbeimengungen}

\subsection{Obduktion und Paraffineinbettung}

Nach der qCT 2, die 4 Wochen nach der Ovx durchgeführt wurde, wurden die Tiere obduziert. Ihnen wurden zahlreiche Organe zur histologischen Untersuchung entnommen. Fast jedes Gewebe der Ratten konnte für spätere Forschungszwecke Verwendung finden. Auch aus dem bei der Tötung gewonnenen Blut wurden verschiedene Serumparameter bestimmt. Unter anderem wurden auch das Herz und der M. gastrocnemius der Skelettmuskulatur chirurgisch herauspräpariert und bis zur Weiterverarbeitung für 24-72 Stunden in zehnprozentigem Formalin konserviert. Anschließend wurden sie durch eine aufsteigende Alkoholreihe entwässert, mit Xylol stabilisiert und zum Schluss in Paraffin eingebettet. Die genauen Einwirkzeiten sind der Tab. $2.2 \mathrm{im}$ Anhang zu entnehmen. Der letzte Schritt wurde mit Hilfe einer Paraffin-Ausgießstation (EG 1060 Leica) vollzogen. Die Herzen wurden mit der anatomischen Herzachse quer zur Mikrotomschnittebene in das Paraffin eingebettet. Mit diesen Paraffinblöcken begann meine experimentelle Arbeit des Versuches.

Die anatomische Herzachse verläuft von der Mitte der Herzbasis zur Herzspitze (Apex). So entstanden beim Schneiden der Paraffinblöcke Querschnitte des Herzens in Höhe der vom linken Ventrikel gebildeten Herzspitze. Auch der $M$. gastrocnemius wurde längs zur Schnittebene in Paraffin eingegossen, sodass Paraffinscheiben mit querangeschnittenen Muskeln entstanden. Die Weiterverarbeitung der bei der Obduktion entnommenen Organe bis hin zur Paraffineinbettung wurde von Frau H. Brüggemann-Meyer, der Medizinischtechnischen Assistentin (MTA), durchgeführt. Zur Veranschaulichung der Gewinnung der Präparate soll die Abb. 2.2 dienen. 


\section{Myokard}

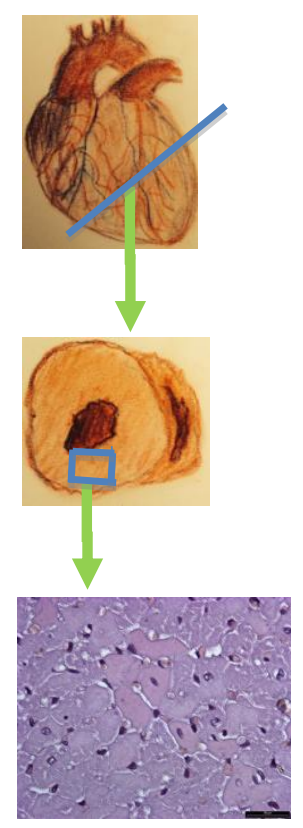

\section{M. gastrocnemius}

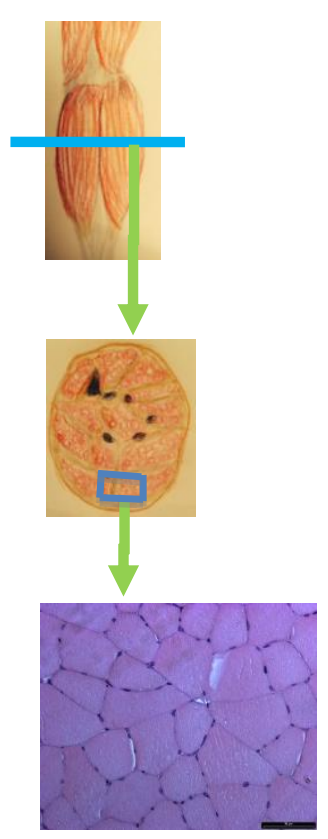

Quellen der Bilder:

Alle Zeichnungen der Organe und mikroskopischen Aufnahmen der Schnitte zu dieser Dissertation habe ich selbst angefertigt.

\section{Abb. 2.2 Gewinnung der Präparate}

\subsection{Herstellung der lichtmikroskopischen Präparate}

\subsubsection{Schnittpräparation}

Am 14.03.2011 begann mit dem Bearbeiten der Paraffinblöcke mein Teil des Versuches. Die Blöcke mit eingebetteten Herzen und $M m$. gastrocnemii wurden mindestens 24 Stunden vor ihrer Verarbeitung bei $-20^{\circ} \mathrm{C}$ in einem Gefrierschrank gelagert. Mit einem RotationsTischmikrotom (Leica 2065 Supercut, Leica Biosystems GmbH Model RM 2135 Fabriknummer 2794/10.2000; Kat.Nr: 050029802) wurden $3 \mu \mathrm{m}$ starke Transversalparaffinscheiben mit den jeweiligen Organen im Zentrum abgeschnitten. Anschließend wurden sie mit einem Pinsel vorsichtig vom Mikrotom in ein entkalktes auf etwa $20^{\circ} \mathrm{C}$ temperiertes Leitungswasserbad transportiert. Nachdem sich jeweils mindestens zehn intakte Paraffinscheiben im Wasserbad befanden, wurden von jedem Organ jedes Tieres zehn Objektträger (Menzel, Superfrost Plus) mit Schnitten aufgezogen. Die Objektträger wurden nach Aufnahme der Schnitte aus dem ersten Wasserbad noch in ein zweites $37^{\circ} \mathrm{C}$ beheiztes Wasserbad getaucht mit dem Ziel der Glättung der Organe in den Paraffinscheiben. Sie wurden anschließend für mindestens 24 Stunden zum Trocknen in einer 
Trockenkammer der Firma Memmert bei $37^{\circ} \mathrm{C}$ deponiert. Im Anschluss wurden sie unterschiedlichen Färbungen unterzogen.

\subsubsection{Hämalaun-Eosin (HE)-Färbung}

Die HE-Färbung, eine Standardfärbung, ist die wichtigste und am häufigsten angewandte histologische Färbemethode und dient in diesem Versuch der lichtmikroskopischen Auswertung der Myozytenflächen von Herz- und Skelettmuskulatur. Jeweils zwei von den zehn mit Organen aufgezogenen Objektträgern eines jeden Paraffinblocks durchliefen den Vorgang der HE-Färbung. Somit wurden pro Organ eines Tieres jeweils 2 Objektträger gefärbt. Die Beschreibung des Ablaufes ist unter 2.A. und die Einwirkzeiten der Substanzen der HE-Färbung in der Tab 2.3 des Anhangs zu finden.

\subsubsection{Elastika-Färbung nach Weigert in Kombination mit der Van-Gieson-Färbung}

Die Elastika-Färbung nach Weigert in Kombination mit der Van-Gieson-Färbung dient zur Darstellung der Anteile elastischer Fasern, der EZM. Die Kombination dieser Färbungen ist ein langbewährtes Hausrezept der Abteilung für Endokrinologie der Universitätsmedizin Göttingen. Sie färbt das aus kollagenen und elastischen Fasern bestehende Bindegewebe spezifisch an. Sie dient in diesem Versuch der lichtmikroskopischen Bestimmung der prozentualen elastischen Faseranteile in Ausschnitten der Skelett- und Herzmuskulatur. Wie zuvor wurden auch hier jeweils zwei der zehn von einer Ratte stammenden mit Skelett- und Herzmuskulatur aufgezogenen Objektträger mittels dieser Methode angefärbt. Der genaue Ablauf der Färbung ist im Anhang unter 3.B. beschrieben und die Einwirkzeiten der Substanzen dieser Färbung sind in der Tab. 2.4 zu finden.

\subsection{Auswertung der gefärbten histologischen Präparate}

Die Gerätekonfigurierung bei der Auswertung bestand aus einem mit einem Computer verbundenen Lichtmikroskop (Axiophat, Zeiss) mit integrierter CCD-Kamera (Olympus ColorView, Soft Imaging System GmbH, Münster). Während meines Versuchs wurde die Software des Programmes zur Auswertung erneuert. So wurden die Myozytenflächen der Skelett- und Herzmuskulatur mit dem Programm Analysis 3.0 analysiert und ausgewertet. Die Bestimmung des Anteils an EZM im skelettmuskulären und myokardialen Gewebe wurde mithilfe der erneuerten Software EYE vollzogen. Die beiden Programme stammen von demselben Hersteller (Olympus, Hamburg) und basieren bei der Anwendung und Auswertung auf den gleichen Prinzipien.

\subsubsection{Skelettmuskelfaserflächenmessung}

Die Flächenmessungen der Myozyten wurden an den mit $H E$ gefärbten Präparaten durchgeführt. In den Skelettmuskulaturpräparaten wurde bei 25-facher Vergrößerung pro 
Objektträger beliebig ein Bildausschnitt mit querangeschnittenen Myozyten unter der Beleuchtungsstärke 4-7 fotografiert. Im Randbereich der Mm. gastrocnemii war der größte Teil an querangeschnittener Skelettmuskelfaserfläche zu finden. In jedem Ausschnitt wurden zehn querangeschnittene Skelettmuskelfasern mittels eines Cursors mit Linien umkreist, wie aus Abb. 2.3 ersichtlich. Somit gingen zwei Ausschnitte und insgesamt 20 Skelettmuskelfaserflächen pro Tier in die Auswertung mit ein.

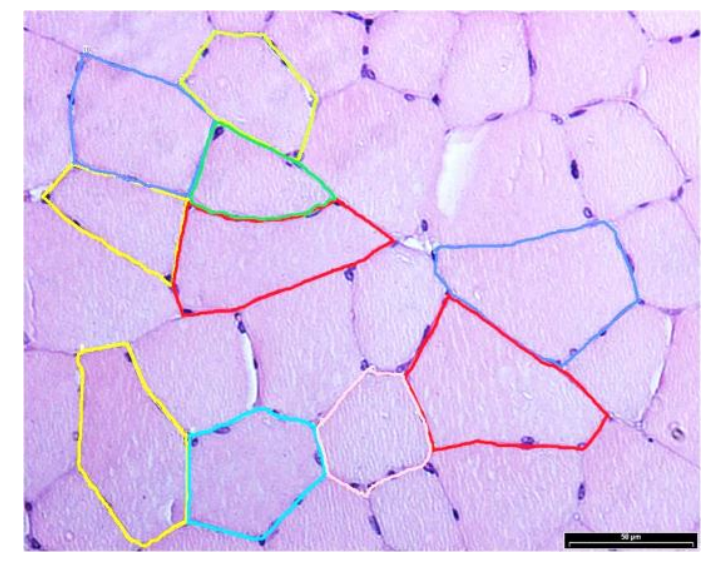

Abb. 2.3 Skelettmuskelfaserflächenmessung

\subsubsection{Kardiomyozytenflächenmessung}

Die Kardiomyozytenflächenmessung erfolgte auf ähnliche Art und Weise. Jedoch wurden hier bei 50-facher Vergrößerung in zwei beliebigen Ausschnitten mit querangeschnittenen Kardiomyozyten pro Objektträger jeweils fünf Myozytenflächen gemessen. Diese Messung wird in Abb. 2.4 dargestellt. Die Herzmuskelzellen besitzen im Querschnitt im Gegensatz zu Skelettmuskelfasern, die randständige Zellkerne verzeichnen, einen zentralen, mittig gelegenen Zellkern. Die querangeschnittenen Kardiomyozytenflächen befanden sich auch hier eher im äußeren Randbereich der Ventrikel. Hier wurden im Gegensatz zur Skelettmuskulatur vier Ausschnitte, jedoch insgesamt auch 20 Kardiomyozytenflächen pro Tier ausgewertet. 


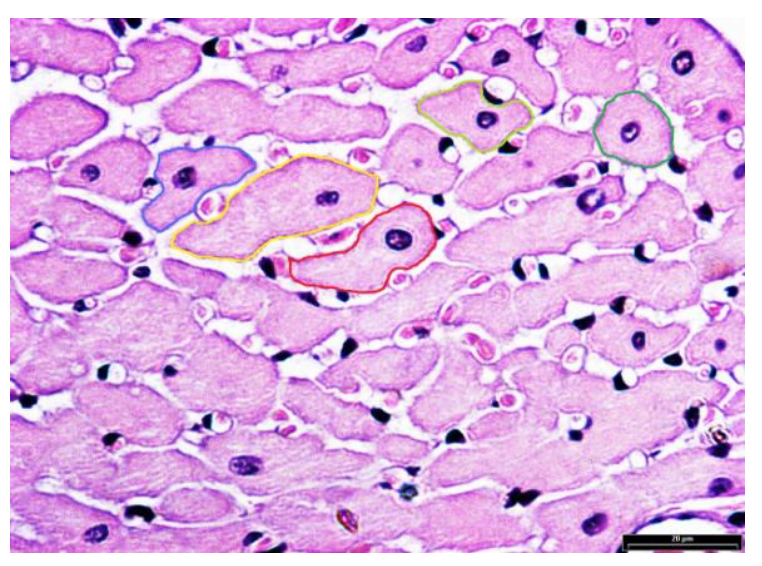

Abb. 2.4 Kardiomyozytenflächenmessung

Das Programm Analysis 3.0 wurde vor der Festlegung des zu analysierenden Bildausschnittes auf die mittels Objektiv und Rad jeweils eingestellte Vergrößerung kalibriert. So konnte das Programm die umfahrenen Flächen messen und in reale Flächenwerte in $\left(\mu \mathrm{m}^{2}\right)$ umrechnen. Die Daten wurden anschließend in Form von Excel-Tabellen gespeichert.

\subsubsection{Bestimmung der elastischen Anteile in der Skelettmuskulatur}

Zur Bestimmung des Anteils an elastischen Fasern, der EZM, im Herz- und Skelettmuskelgewebe fanden die mit der Elastika nach van Gieson angefärbten Präparate Verwendung. Die realitätsgetreue EZM- und Skelettmuskelflächenangabe von EYE erfolgte wie bei der HE-Auswertung automatisch, nachdem Vergrößerungseinstellungen von Objektiv und dem zusätzlichen Vergrößerungsrad in dem Programm eingegeben wurden.

Bei der Auswertung der Skelettmuskulatur wurden bei 3,125-facher Vergrößerung zwei Ausschnitte mit querangeschnittenen Myozyten, die im Randbereich aufzufinden waren, mit eingeschlossenem Epimysiumanteil nach dem Zufallsprinzip ausgewählt. Somit wurden vier Ausschnitte pro Tier ausgewertet. In diesen Ausschnitten wurden die durch die ElastikaFärbung pink/rot angefärbten EZM-Bestandteile manuell grün flächig exakt markiert. Auf die gleiche Art und Weise wurde die Skelettmuskulatur in den entsprechenden Ausschnitten mit der Farbe rot markiert. Zum Verständnis der soeben beschriebenen Eye-Auswertung dienen die folgenden Abbildungen 2.5 und 2.6. 


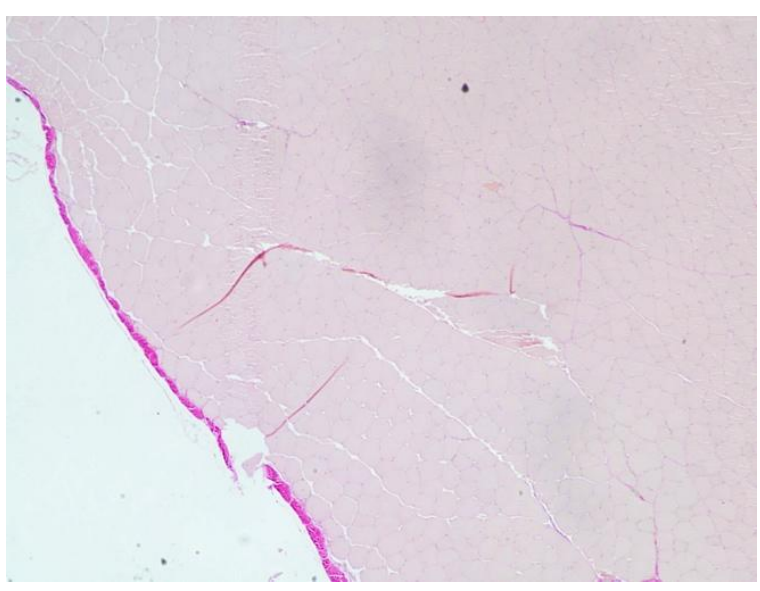

Abb. 2.5

Querschnitt Skelettmuskulatur

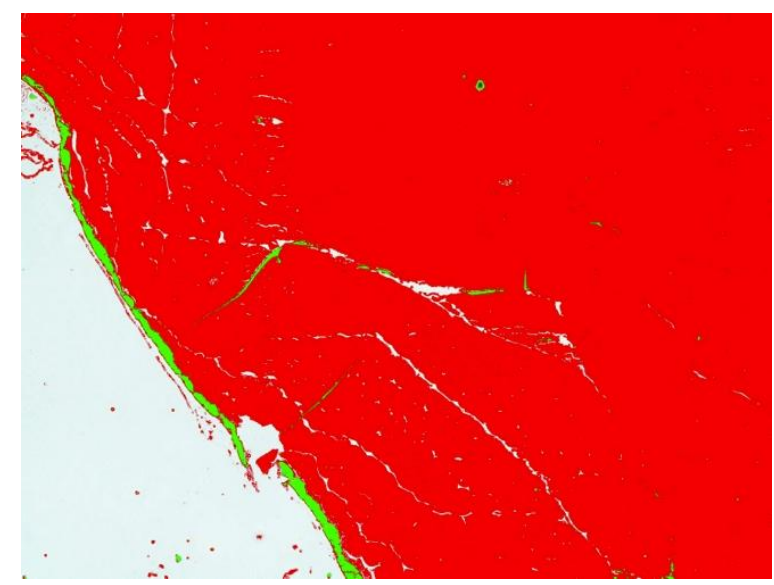

Abb. 2.6

EZM- und Skelettmuskulaturflächenmessung

Die Eye Software besitzt die Fähigkeit, nach erfolgter Kalibrierung bei den folgenden Schnitten die durch die Elastika-Färbung wiederum gleich angefärbten Anteile an EZM und Skelettmuskulatur zu identifizieren, auszumessen und den prozentualen Anteil bezogen auf einen Ausschnitt wiederzugeben. Die prozentualen Skelettmuskel- und EZM-Anteile der Ausschnitte wurden wiederum als Exceldateien gespeichert. Zunächst wurde jeweils eine Gesamtexceltabelle der prozentualen EZM- und der Skelettmuskulatur-Flächenwerte bezogen auf einen Ausschnitt erzeugt. Zudem wurde, um die Aussagekraft zu erhöhen der prozentuale EZM-Flächenanteil bezogen auf die Skelettmuskelfläche in einem Ausschnitt mit Hilfe der folgenden Formel berechnet.

\section{$\left(A_{E Z M} \times 100\right) \div A_{\text {Skelettmuskel }}=$ Prozentualer EZM-Anteil bezogen auf die}

\section{Skelettmuskelfläche in einem Ausschnitt}

\subsubsection{Bestimmung der elastischen Anteile in der Herzmuskulatur}

Auch bei der Auswertung der Herzmuskulatur wurden zur Bestimmung der elastischen Anteile die durch die Elastika nach van Gieson rot angefärbten Bestandteile der EZM und die Kardiomyozytenfläche jeweils in zwei beliebigen Ausschnitten pro Objektträger mittels des Eye Computerprogrammes gemessen. Die Funktionen von EYE wurden bei der Auswertung der Herzschnitte, wie zuvor bei der Skelettmuskulatur beschrieben, auf die gleiche Art und Weise genutzt. Wiederum wurde der EZM-Anteil grün und die Herzmuskelfläche rot markiert. Diese Anteile wurden wie zuvor vom Eye-Programm gemessen. Dieses erfolgte wiederum im Randbereich der Schnitte, in denen der größte Teil an quergeschnittenen Kardiomyozyten zu finden war. Dieses Mal jedoch fand eine 25-fache Vergrößerung Anwendung. Zudem wurde hier nur der interzelluläre EZM-Gehalt und nicht wie in der Skelettmuskulatur der zudem der randständige EZM-Anteil, der durch das Epimysium 
gebildet wird, bestimmt. Zum Verständnis der zuvor beschriebenen Eye-Auswertung sollen die folgenden Abbildungen 2.7 und 2.8 dienen.

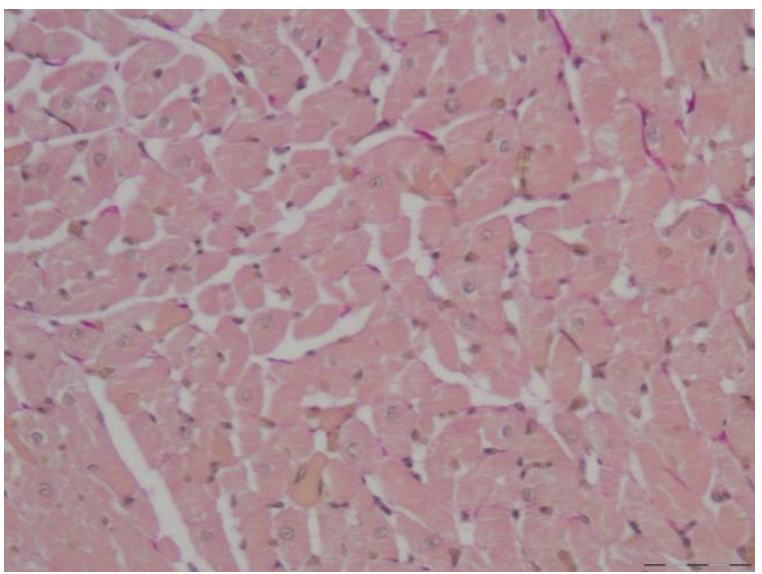

Abb. 2.7

Querschnitt Herzmuskulatur

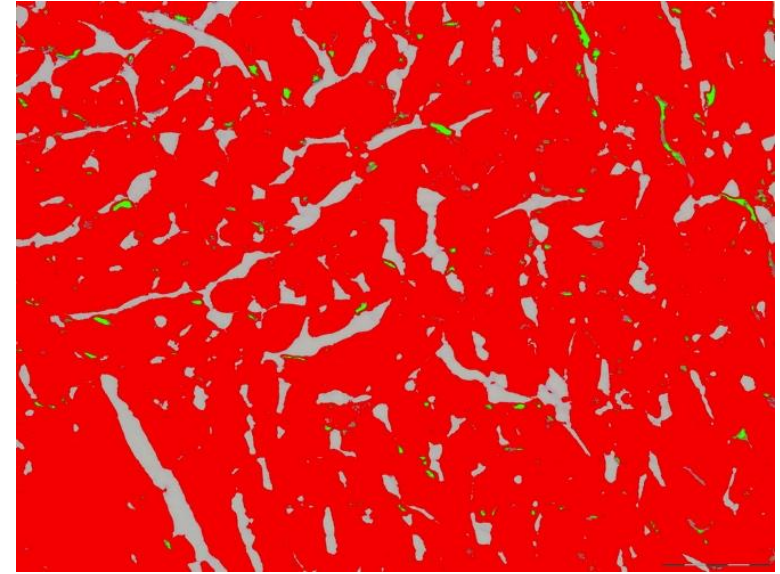

Abb. 2.8

EZM- und Herzmuskulaturflächenmessung

Die prozentualen Skelettmuskel- und EZM- Anteile der Ausschnitte wurden wiederum in Form von Exceldateien gespeichert. Anschließend wurde wieder jeweils eine Gesamtexceltabelle der prozentualen EZM- und der Skelettmuskulatur-Flächenwerte, bezogen auf einen Ausschnitt, erzeugt. Wie zuvor wurde die Aussagekraft durch das Berechnen des prozentualen EZM-Flächenanteils, bezogen auf die Herzmuskelfläche, durch die folgenende Formel gesteigert.

\section{$\left(A_{E Z M} \times 100\right) \div A_{\text {Herzmuskel }}=$ Prozentualer EZM-Anteil bezogen auf die Herzmuskelfläche in einem Ausschnitt}

\subsection{Statistische Auswertung der Excel-Daten}

Die aus der histologischen Auswertung hervorgegangenen einzelnen Excel-Werte der jeweils gleichen Futtergruppen und gleichen Flächenmessungen wurden als erstes als Gesamtexceltabellen zusammengefügt. Anschließend wurden die Exceldaten zur graphischen Darstellung und zur statistischen Auswertung in das Computerprogramm GraphPad Prism 5 (San Diego, USA) überführt. Zur vergleichbaren Darstellung der Daten wurden Säulendiagramme gewählt. Es wurde das Signifikanzniveau $p<0,05$ festgelegt. Die Mittelwerte und Standardabweichungen wurden ermittelt. Für den Vergleich der unterschiedlichen Futtergruppen mit der Kontrollgruppe führte man jeweils einen T-test zwischen diesen mittels Prism durch. Die Frage der Signifikanz der Gruppen im Vergleich zur Kontrollgruppe wurde durch eine Varianzanalyse beantwortet. Um die Flächenmesswerte der aus CR extrahierten Gesamtsaponin- und Gesamtrestfraktion, als auch deren Subfraktionen sinnvoll auswerten, vergleichen und deuten zu können sind jeweils in den im 
Ergebnissteil dargestellten Graphen sowohl der Effekt bei den mit Östrogen gefütterten Tieren (EB-Gruppe) als auch die Werte der Kontrollgruppe beigefügt. 


\section{Ergebnisse}

3.1 Futteraufnahme und Körpergewichte

Während der Fütterungsphase wurde die Menge an gefressenem Futter bestimmt, und somit die mittlere Futter- und Substanzaufnahme errechnet. Wie in der Einleitung bereits dargestellt, beruhen die gewählten Substanzmengen auf Berechnungen und Ergebnissen dieser Abteilung und wurden allen Doktoranden des Versuches zur Verfügung gestellt. Die genauen Mengen sind der Tab. 3.1 zu entnehmen.

\begin{tabular}{|c|c|c|c|c|c|}
\hline Futterart & Gruppe & $\begin{array}{l}\text { Anzahl } \\
\text { der Tiere }\end{array}$ & $\begin{array}{l}\text { Dosis in } \\
\text { mg/kg Futter }\end{array}$ & Futteraufnahme & Substanzaufnahme \\
\hline Ko & Ko & 10 & keine & 17,95 & keine \\
\hline Estradiolbenzoat & EB & 10 & 10 & $10,81^{*}$ & 0,108 \\
\hline Saponinfraktion & Sap & 10 & 117,6 & 17,17 & 2,019 \\
\hline Restfraktion & Rest & 10 & 382,35 & 19,03 & 7,26 \\
\hline Subfraktion 1 der Saponinfraktion & S1 & 10 & 31,2 & 18,37 & 0,573 \\
\hline Subfraktion 2 der Saponinfraktion & S2 & 10 & 46,06 & 17,63 & 0,802 \\
\hline Subfraktion 3 der Saponinfraktion & S3 & 10 & 46,04 & 19,56 & 0,900 \\
\hline Subfraktion 1 der Restfraktion & R1 & 10 & 276,81 & 18,75 & 5,190 \\
\hline Subfraktion 2 der Restfraktion & R2 & 10 & 75,37 & 18,71 & 1,410 \\
\hline Subfraktion 3 der Restfraktion & R3 & 10 & 35,979 & 18,52 & 0,666 \\
\hline
\end{tabular}

${ }^{*} \mathrm{p}<0,05$ vs Ko

\section{Tab. 3.1 Substanzaufnahme der Futtergruppen}

Zur besseren Übersicht der Futteraufnahme der einzelnen Gruppen im Vergleich soll die folgende Tab. 3.1 dienen. 


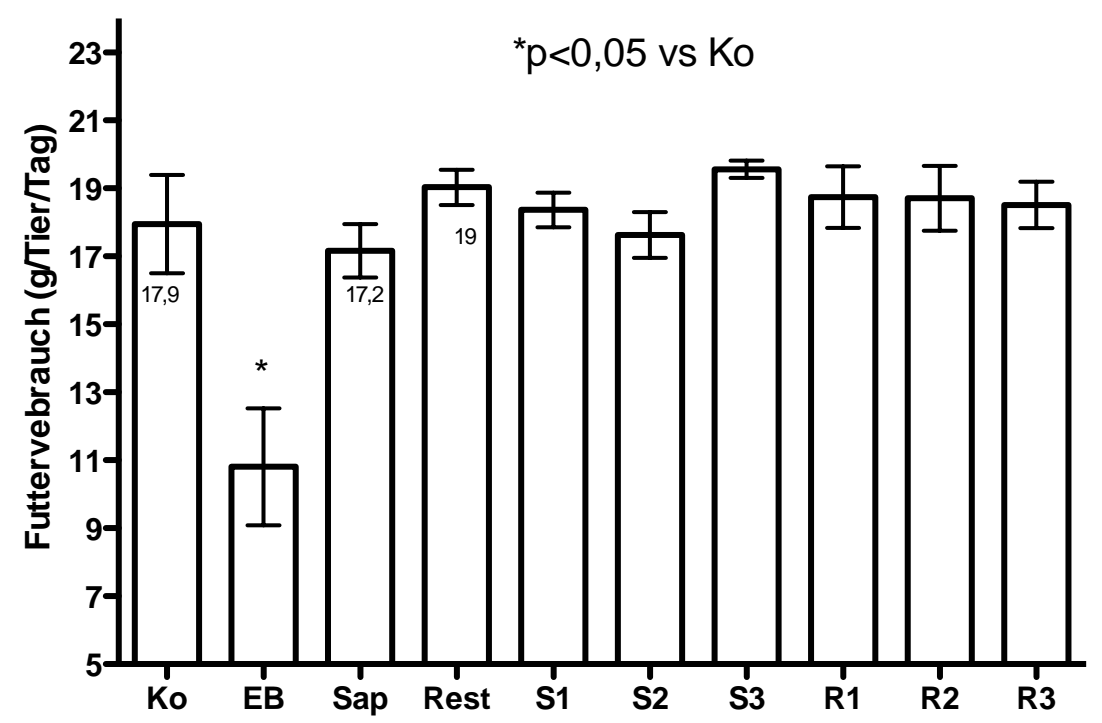

Abb. 3.1 Der Effekt von EB, der aus CR extrahierten Saponin- und Restfraktion, und deren Subfraktionen

(28 Tage per Futter bei ovx Ratte) auf den Futterverbrauch im Versuch

Die Tiere wurden einmal bei Ankunft (qCT1), anschließend vor der Ovx und zuletzt vor der Obduktion (qCT2) gewogen. Dadurch konnte die Gewichtsveränderung zwischen der Ankunft und dem Ende der vierwöchigen Fütterung bestimmt werden, die im folgenden Graphen (Abb. 3.2) veranschaulicht wird.

Die Angaben über Futter und Körpergewichte der Ratten stehen allen Studenten der Arbeitsgruppe FUTSUB zur gemeinsamen Nutzung zur Verfügung. Die studentischen Mitglieder dieser Arbeitsgruppe sind Lisa Langer, Nina Danilova, Viktoria Blaschek, Tobias Dietwald, Robert Rehmann, Maria Tschernov, Hans Grats, Nicole Eder und Vera Stahnke und ich. 


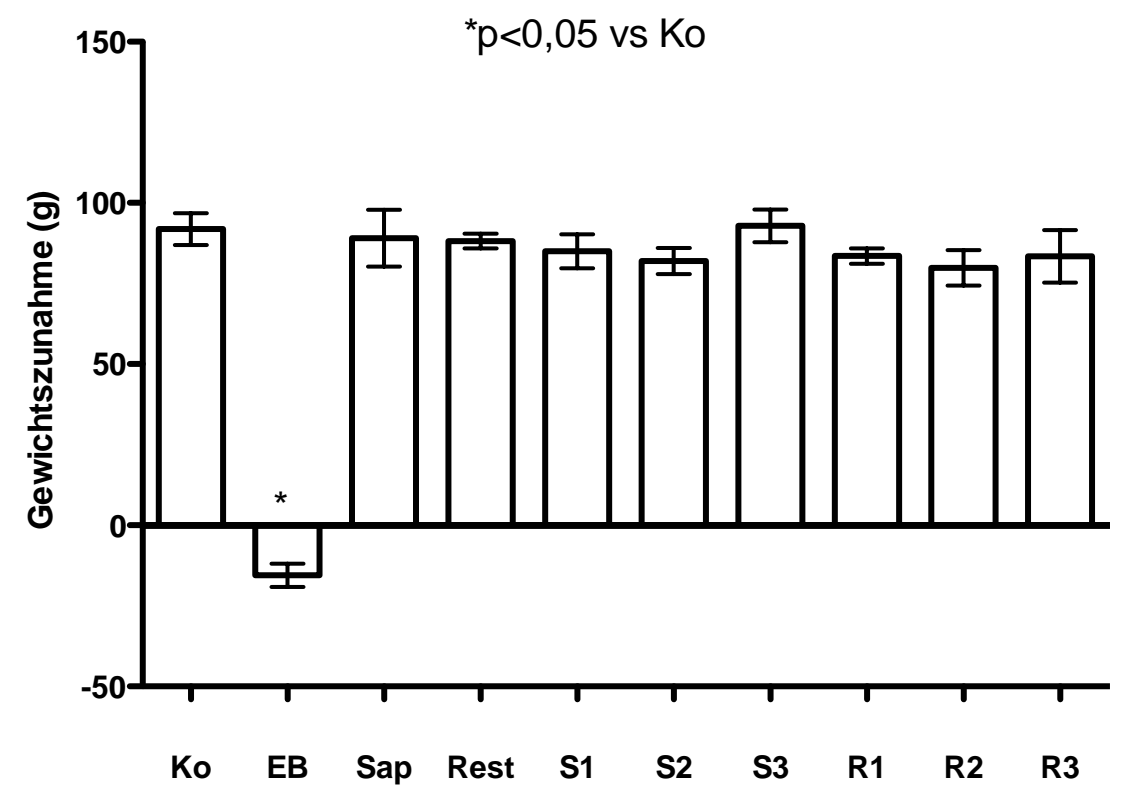

Abb. 3.2 Der Effekt von EB, der aus CR extrahierten Saponin- und Restfraktion, deren Subfraktionen

(28 Tage per Futter bei ovx Ratte) auf die Gewichtszunahme im Versuch

Aus dem Graphen geht hervor, dass alle Tiere, außer der EB-Gruppe, im gleichen angemessenen Maße zwischen $80 \mathrm{~g}$ und $95 \mathrm{~g}$ ohne signifikante Unterschiede, zugenommen haben. Diese Tatsache geht mit dem Wohlbefinden der Tiere einher, da sie unter vom Tierschutzverein akzeptierten Bedingungen gehalten wurden. Die EB-Gruppe verzeichnete eine angemessene östrogene Gewichtsregulation.

Wenn jeweils die Werte der Futteraufnahme der einzelnen Gruppen mit dem jeweiligen Gewichtszuwachs ins Verhältnis gesetzt werden, zeigt sich eine erwartete Proportionalität der Werte. 
3.2 Ergebnisse der Myozytenflächenmessungen von Skelett- und Herzmuskulatur

\subsubsection{Ergebnisse der Skelettmuskelfaserflächenmessung}

Als Auswertungsgrundlage gingen als primäre Rohdaten je zwei Ausschnitte mit je 10 Skelettmuskelfaserflächen also insgesamt 20 Muskelfaserflächen pro Tier in die Auswertung mit ein.

${ }^{*} \mathrm{p}<0,05$ vs Ko

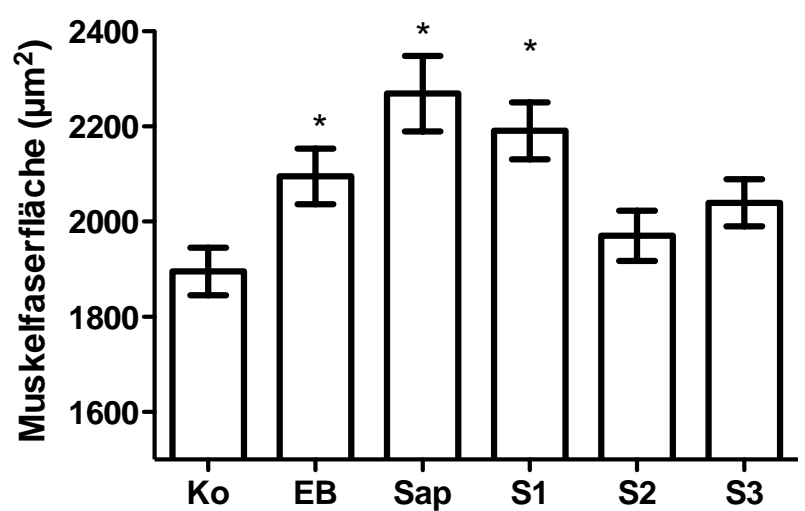

\section{Abb. 3.3 Der Effekt von EB, der aus $C R$ extrahierten Saponinfraktion und ihren Subfraktionen auf die Skelettmuskelfaserfläche}

In der vorhergestellten Abb. 3.3 wird der Effekt der aus $C R$ extrahierten Saponinfraktion und inrer Subfraktionen (S1, S2 und S3) auf die Skelettmuskelfaserfläche dargestellt. Auf der xAchse des Graphs ist die Skelettmuskelfaserfläche in $\mu \mathrm{m}^{2}$ angegeben. Auf der $\mathrm{y}$-Achse sind die verschiedenen Gruppen im Vergleich zu finden. Diese Angaben gelten auch für die folgenden Graphen der Myozytenflächenmessungen des Abschnittes 3.2.. Bei der Herzmuskulatur (3.2.2.) ist an Stelle der Skelettmuskelfaserfläche die Kardiomyozytenfläche dargestellt.

Die Skelettmuskelfaserflächenwerte dieser Gruppen schwanken zwischen 1900 und 2300 $\mu \mathrm{m}^{2}$.

Aus dem Graphen geht hervor, dass die Skelettmuskelfaserfläche unter dem Einfluss der Saponinfraktion, der S1-Subfraktion und der E2-Gruppe signifikant im Vergleich zur Kontrollgruppe zugenommen hat.

Sowohl die S2-Subfraktion als auch die S3-Subfraktion verzeichneten zwar auch größere Mittelwerte der Skelettmuskelfaserfläche, jedoch nur Tendenzen, keine Signifikanzen 
${ }^{*} \mathrm{p}<0,05$ vs Ko

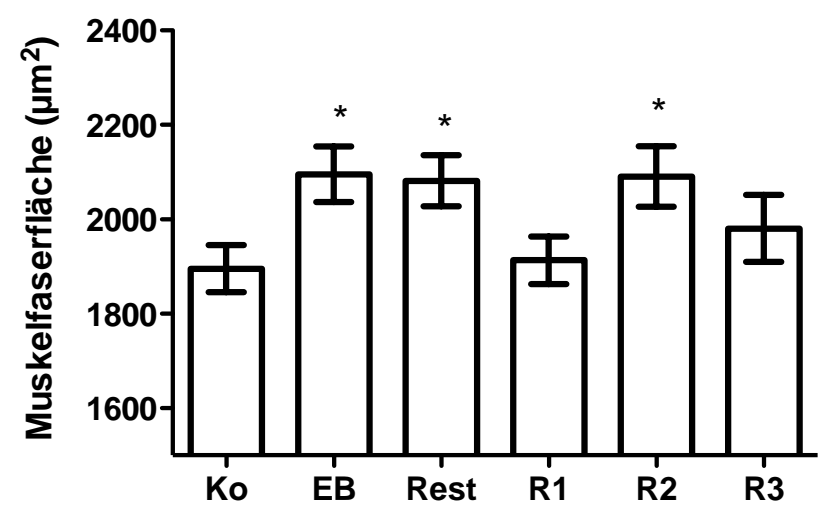

\section{Abb. 3.4 Der Effekt von EB, der aus $C R$ extrahierten Restfraktion und ihren Subfraktionen auf die Skelettmuskelfaserfläche}

In der Abb. 3.4 ist der Effekt der aus $C R$ extrahierten Restfraktion und ihrer Subfraktionen (R1, R2 und R3) auf die Skelettmuskelfaserfläche dargestellt. Die Skelettmuskelfaserflächenwerte dieser Gruppen schwanken zwischen 1900 und $2100 \mu^{2}$. In dieser Auswertung zeigen die Skelettmuskelfaserflächenwerte der Gesamtrestfraktion, der R2Subfraktion und wiederum der EB-Gruppe signifikant größere Flächen im Vergleich zur Kontrollgruppe.

Die R1- und R3-Subfraktion weisen keine signifikanten Vergrößerungen auf, allenfalls geringe Tendenzen. 


\subsubsection{Ergebnisse der Kardiomyozytenflächenmessung}

Als Auswertungsgrundlage gingen als primäre Rohdaten hier im Gegensatz zur Skelettmuskulatur vier Ausschnitte, jedoch insgesamt auch 20 Kardiomyozytenflächen pro Tier in die Auswertung mit ein.

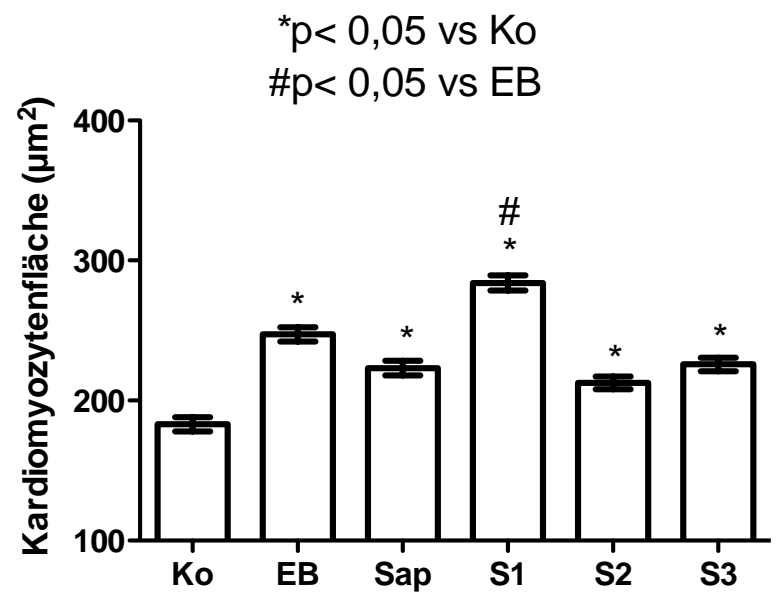

\section{Abb. 3.5 Der Effekt von EB, der aus $C R$ extrahierten Saponinfraktion und ihren Subfraktionen auf die Kardiomyozytenfläche}

Die Abb. 3.5 zeigt den Effekt der aus $C R$ extrahierten Saponinfraktion und ihrer Subfraktionen (S1, S2 und S3) auf die Kardiomyozytenfläche.

Die Kardiomyozytenflächenwerte dieser Gruppen schwanken zwischen 190 und $290 \mu \mathrm{m}^{2}$.

Der Graph zeigt, dass die Kardiomyozytenfläche unter dem Einfluss der Saponinfraktion, der S1-, S2-, und S3-Subfraktion und der EB-Gruppe, also bei allen hier gezeigten Gruppen, signifikant im Vergleich zur Kontrollgruppe zugenommen hat. Des Weiteren verzeichnet die Kardiomyozytenfläche der S1-Gruppe zusätzlich im Vergleich mit der EB-Gruppe einen signifikanten und den insgesamt stärksten Größenzuwachs. 


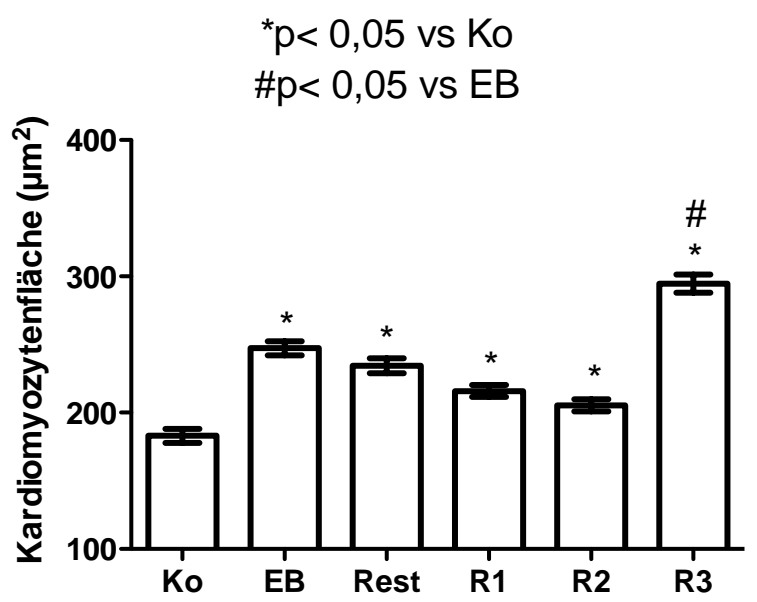

Abb 3.6 Der Effekt von EB, der aus CR extrahierten Restfraktion und ihren Subfraktionen auf die Kardiomyozytenfläche

In der Abb. 3.6 wird der Effekt der aus $C R$ extrahierten Restfraktion und ihrer Subfraktionen (R1, R2 und R3) auf die Kardiomyozytenfläche angezeigt.

Die Kardiomyozytenflächenwerte dieser Gruppen schwanken zwischen 190 und $300 \mu \mathrm{m}^{2}$.

Dem Graph ist zu entnehmen, dass die Kardiomyozytenfläche unter dem Einfluss der Restfraktion, all ihrer Subfraktionen(R1, R2 und R3) und der EB-Gruppe, also wiederum bei allen hier dargestellten Gruppen, signifikant im Vergleich zur Kontrollgruppe zugenommen hat. Des Weiteren verzeichnet die Kardiomyozytenfläche der R3-Gruppe zusätzlich im Vergleich mit der EB-Gruppe einen signifikanten und den insgesamt stärksten Größenzuwachs. 
3.3 Bestimmung der elastischen Anteile in Skelett- und Herzmuskulatur

3.3.1 Elastika-Auswertung Skelettmuskulatur

${ }^{*} \mathrm{p}<0,05$ vs Ko

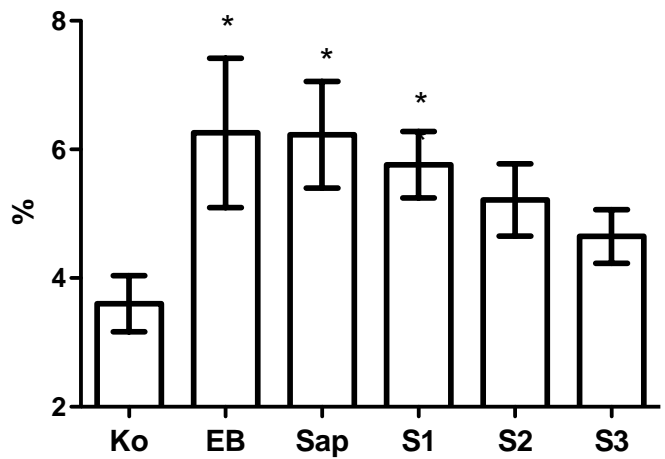

\section{Abb. 3.7 Der Effekt von EB, der aus $C R$ extrahierten Saponinfraktion und ihren Subfraktionen auf den Anteil an elastischen Fasern bezogen auf die Skelettmuskelfaserfläche}

In der vorangehenden Abb. 3.7 ist der Effekt der aus $C R$ extrahierten Saponinfraktion und ihren Subfraktionen (S1, S2 und S3) auf die elastischen Anteile der Skelettmuskulatur in Bezug auf die Skelettmuskelfaserfläche dargestellt. Der Berechnungsweg dieser Werte ist dem Material- und Methodenteil zu entnehmen.

Der elastische Faseranteil bezogen auf den Muskelfaseranteil in den jeweiligen Ausschnitten dieser Gruppen schwankt zwischen 3,5 und 6,5\%.

Der Graph zeigt eine signifikante Zunahme des elastischen Faseranteils unter dem Einfluss der Saponinfraktion, ihrer S1- und S2-Subfraktion als auch der EB-Gruppe im Vergleich zur Kontrollgruppe. Die S3-Subfraktion verursacht keine signifikante Zunahme der elastischen Fasern im Vergleich mit der Kontrollgruppe. 


$$
{ }^{*} p<0,05 \text { vs Ko }
$$

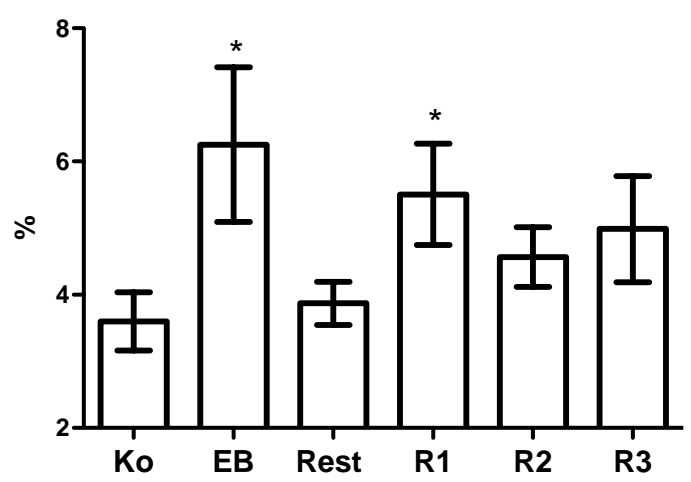

\section{Abb. 3.8 Der Effekt von EB, der aus CR extrahierten Restfraktion und ihren Subfraktionen auf den Anteil an elastischen Fasern bezogen auf die Skelettmuskelfaserfläche}

Der Abb. 3.8 ist der Effekt der aus $C R$ extrahierten Restfraktion und ihrer Subfraktionen (R1, R2 und R3) auf die elastischen Anteile der Skelettmuskulatur im Bezug auf die Skelettmuskelfaserfläche zu entnehmen.

Der elastische Faseranteil bezogen auf den Muskelfaseranteil in den jeweiligen Ausschnitten dieser Gruppen schwankt wie bei den Saponinen zwischen 3,5 und 6,5 \%.

Nur unter dem Einfluss der R1-Subfraktion und der EB-Gruppe im Vergleich mit der Kontrollgruppe ist eine signifikante Zunahme des Anteils an elastischen Fasern zu beobachten. Die Restfraktion und auch ihre R2- und R3-Subfraktionen weisen keine signifikante Zunahme der elastischen Fasern im Vergleich mit der Kontrollgruppe auf. 


\subsubsection{Elastika-Auswertung Herzmuskulatur}

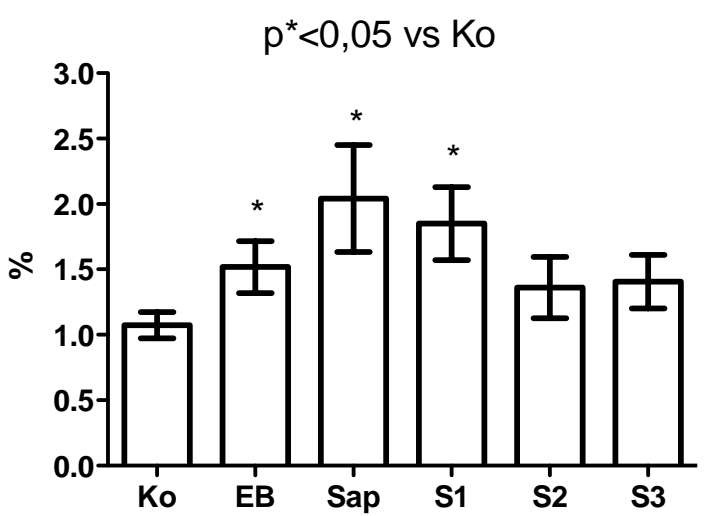

Abb. 3.9 Der Effekt von EB, der aus $C R$ extrahierten Saponinfraktion und ihren Subfraktionen auf den Anteil an elastischen Fasern bezogen auf die Kardiomyozytenfläche

Die Abb. 3.9 zeigt den Effekt der aus $C R$ extrahierten Saponinfraktion und ihrer Subfraktionen (S1, S2 und S3) auf die elastischen Anteile der Herzmuskulatur in Bezug auf die Kardiomyozytenfläche. Die Berechnung der Werte ist wiederum im Material- und Methodenteil beschrieben.

Der elastische Faseranteil bezogen auf den Kardiomyozytenflächenanteil in den jeweiligen Ausschnitten dieser Gruppen schwankt zwischen 1 und $2 \%$.

Eine signifikante Zunahme des elastischen Faseranteils unter dem Einfluss der Saponinfraktion, ihrer S1-Subfraktion und auch der EB-Gruppe im Vergleich mit der Kontrollgruppe geht aus dem Graphen hervor. Die S2- und S3-Subfraktion führen zu keiner signifikanten Zunahme der elastischen Fasern im Vergleich mit der Kontrollgruppe. 


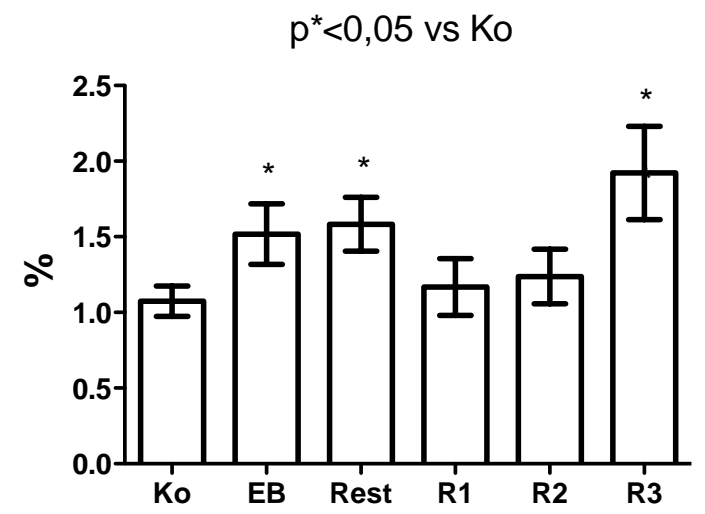

\section{Abb. 3.10 Der Effekt von EB, der aus $C R$ extrahierten Restfraktion und ihren Subfraktionen auf den Anteil an elastischen Fasern bezogen auf die Kardiomyozytenfläche}

In der Abb. 3.10 ist der Effekt der aus $C R$ extrahierten Restfraktion und ihren Subfraktionen (R1, R2 und R3) auf die elastischen Anteile der Herzmuskulatur in Bezug auf die Kardiomyozytenfläche zu sehen.

Der elastische Faseranteil bezogen auf den Kardiomyozytenflächenanteil in den jeweiligen Ausschnitten dieser Gruppen schwankt wie bei den Saponinen zwischen 1 und $2 \%$.

Unter dem Einfluss der Restfraktion, ihrer R3-Subfraktion und der EB-Gruppe im Vergleich mit der Kontrollgruppe ist eine signifikante Zunahme des Anteils an elastischen Fasern zu beobachten. Die R1- und R2-Subfraktionen zeigen keine signifikante Zunahme der elastischen Fasern im Vergleich zur Kontrollgruppe. 


\section{Diskussion}

\subsection{Relevanz}

Die dieser Arbeit zugrunde liegenden Experimente sollten die Auswirkung der aus $C R$ extrahierten Fraktionen und ihren Subfraktionen auf die Herz- und Skelettmuskulatur der Sprague-Dawley-Ratte als Teil des Forschungsprojektes (AZ-838-081.4.2009- 31.3.2012) Osteoporoseprophylaxe mit pflanzlichen Wirkstoffen der Bayerischen Forschungsstiftung untersuchen. Hierzu wurde der Gesamtextrakt zunächst in seine 2 Fraktionen, die Saponinund die Restfraktion und diese zudem jeweils in ihre 3 Subfraktionen S1, S2, S3 bzw. R1, R2 und R3 aufgeteilt. Diese exakte Aufspaltung des Extraktes ist ein Novum.

Nach 4-wöchiger Verabreichung der einzelnen Substanzen an die ovx Versuchstiere fanden sich die vorliegenden Ergebnisse. Sie beruhen auf der Auswertung histologischer Schnitte mittels verschiedener Messungen. Nach statistischer Aufbereitung der gewonnenen Daten wurden die Ergebnisse jeweils mit der Kontrollgruppe verglichen. Die histologische Untersuchung der Auswirkung der einzelnen Fraktionen auf die Struktur des Herz- und Skelettmuskelgewebes ist ebenfalls ein Novum. Daher ist ein Vergleich mit internationaler Literatur nicht möglich. In zahlreichen Versuchen dieser Abteilung und auch in anderen Forschungseinrichtungen im Inland und Ausland konnte eine osteoprotektive Wirkung von $C R$ festgestellt werden (Seidlová-Wuttke et al. 2003b; Wuttke et al. 2006). Aus diesen Ergebnissen resultiert das Interesse an der genaueren Funktionsweise von $C R$ auf die Skelettmuskulatur als Teil des muskuloskelettalen Systems.

Wie bereits beschrieben, reagieren nahezu alle Organe der Ratte und auch des Menschen auf einen manifesten Östrogenmangel, der bei unseren Versuchstieren mittels Ovx hervorgerufen wurde. Die Ovx stellte sicher, dass ausschließlich die verabreichten Substanzen auf die Gewebe wirkten und nicht ovariell produzierte Östrogene, die unter physiologischen Bedingungen starken Einfluss auf jegliches Körpergewebe sowohl der Ratte als auch des Menschen haben. Die Synthese insbesondere des wirksamsten Vertreters der Östrogene, des Östradiols, im Fettgewebe, den Nieren und Nebennieren ist so gering, dass sie in diesem Versuch vernachlässigt werden kann (Karow und Lang-Roth 2012; KleineGunk 2009). Um jeglichen nahrungsbedingten östrogenartigen Effekt auszuschließen, erhielten die Versuchstiere bis zur Verabreichung der zu untersuchenden Substanzen ausschließlich sojafreies Futter. Durch diese definierten hormonellen Bedingungen konnte in diesem Versuch die genaue Wirkung der Bestandteile von CR BNO 1055/C001 auf die Herzund Skelettmuskulatur unter Östrogenmangel untersucht werden. 


\subsection{Cimicifuga racemosa BNO 1055/C001}

In vorangegangenen Versuchen dieser Abteilung wurde der Extrakt CR BNO 1055/C001 bisher nur in seine zwei großen Fraktionen, die Saponin- und die Restfraktion aufgespalten. Erstmalig wurden jedoch in diesem Versuch die Subfraktionen der Saponin- (S1, S2, S3) und Restfraktion (R1, R2, R3) extrahiert und untersucht.

$C R$ vermindert signifikant klimakterische Hitzewallungen und die Produktion von Nachtschweiß (Wuttke et al. 2006; Seidlová-Wuttke 2003a). Der Extrakt besitzt osteo-protektive Eigenschaften und reduziert zudem das paratibiale und intraabdominelle Fettgewebe (Seidlová-Wuttke et al. 2003b). Zudem entfaltet CR im Vergleich zur HRT vorteilhafterweise keine proliferationsfördernde Wirkung auf den Uterus und die Vagina (Liske 1998; SeidlováWuttke et al. 2003a; Seidlová-Wuttke et al. 2003b) und birgt auch kein erhöhtes Brustkrebsrisiko in sich (Liske 1998). Die Untersuchung der Wirkung der aus CR extrahierten Saponin- und Restfraktion und deren Subfraktionen auf die Skelett- und Herzmuskulatur ist ein Novum.

Es zeigte sich, dass die Wirkung von $C R$ nicht auf der direkten Induktion des ER $\alpha$ - oder ER $\beta$ -Östrogenrezeptors und auch nicht auf der anderer Steroidrezeptoren beruht. Neben der Tatsache, dass es keinerlei Wirkung auf jegliche Östrogenrezeptoren besitzt, konnten zudem in mehreren Studien auch selektive östrogenmodulierende Eigenschaften als "Selektiver Östrogen Rezeptor Modulator" (SERM), wie noch vor einigen Jahren vermutet wurde, ausgeschlossen werden (Seidlová-Wuttke 2003a; Wuttke et al. 2006; Liu et al. 2001).

Die exakte Wirkungsweise von $C R$, seiner Fraktionen und Subfraktionen ist jedoch in weiten Bereichen noch unbekannt und daher Gegenstand der Forschung.

Es besteht die Vermutung, dass Wirkstoffe von $C R$ Neurotransmittersysteme und ggf. das Serotoninsystem beeinflussen und so Wirkung entfalten. Insbesondere könnte das in allen Fraktionen und Subfraktionen enthaltene Methylserotonin (Abb. 1.2) eine entscheidende Rolle bei der Wirkungsentfaltung von $C R$ spielen.

\subsection{Analyse der Ergebnisse}

\subsubsection{Futteraufnahme der Versuchstiere}

Die Zuordnung der Ratten in verschiedene Futtergruppen ist der Einleitung und dem Material- und Methodenteil zu entnehmen. Wie bereits erwähnt ließ sich in Kenntnis einer durchschnittlichen Futteraufnahme der Ratte von 17-18 g pro Tag und der Menge der diesem Futter beigemengten CR Gesamtsubstanz sowie deren prozentualer Zusammensetzung der Anteil jeder einzelnen Fraktion bestimmen. Die Dosis in mg/kg Futter sowie die 
Futteraufnahme ist in Tab. 2.1 beschrieben. Die Dosis der Subfraktionen entspricht ihrem Anteil an einer bekannten wirksamen Menge CR BNO 1055 Gesamtextrakt von ca. 9 mg/d. Damit wurde sichergestellt, dass jedem Tier durch die jeweilige Subfraktion die gleiche Menge an Inhaltsstoffen zugeführt wurde, wie im Gesamt $C R$ Extrakt vorhanden war.

Bei den mit EB alimentierten Ratten war im Gegensatz zu den Tieren der Vergleichsgruppen eine Gewichtsabnahme in Höhe von etwa $20 \mathrm{~g}$ zu verzeichnen, da Östrogene mittels direkter Hemmung des Appetitzentrums ein früheres Sättigungsgefühl während der Nahrungsaufnahme bewirken und den Bewegungstrieb fördern (Luppa 2001). Östrogene hemmen die Lipogenese in den Adipozyten. Insofern begünstigt die Abwesenheit von Östrogenen im Klimakterium die Entstehung von Adipositas (Faulds et al. 2012). Die anorektische Wirkung der Östrogene führt zu einem beschleunigten Stoffwechsel, wodurch die Tiere dieser Futtergruppe wie bereits in früheren Versuchen die geringsten Körpergewichte aufwiesen.

Die Tatsache, dass alle anderen Tiere vergleichbare Gewichte aufwiesen, kann als Bestätigung dienen, dass die Dosierungen der einzelnen Fraktionen richtig gewählt und sie unter artgerechten Bedingungen gehalten wurden.

\subsubsection{Skelettmuskulatur}

\subsubsection{Skelettmuskelfaserfläche}

Die Skelettmuskelfaserfläche sagt etwas über die Dicke der einzelnen Skelettmuskelfasern aus und ist daher indirekt ein Maß für die Kraft des Muskels.

Östrogene entfalten ihre Wirkung in der Skelettmuskulatur durch Einwirkung auf ER $\alpha$ und ER $\beta$ (Kalbe et al. 2007). Prämenopausal ist die Konzentration an Östrogenen in der Muskulatur etwa dreimal so hoch wie in der Postmenopause (Pollänen et al. 2011). Wie auch andere Substanzen besitzen Östrogene eine antioxidative Wirkung in der Skelettmuskulatur und schützen so vor einer Übersäuerung (Bloch und Schmidt 2004). Dadurch wirken sie im Muskel bei starker Belastung möglichen Zellschädigungen und Gewebsentzündungen entgegen. Verschiedene Untersuchungen zeigen unterschiedliche Ergebnisse des anabolen Effekts des Östrogens auf die Muskulatur. Es überwiegt jedoch die Ansicht, dass Östrogen anabol auf den Skelettmuskel wirkt (Brown 2008). Wie daher zu erwarten war, ergab sich auch in unserem Versuch eine signifikante Zunahme der Muskelfaserfläche unter dem Einfluss von EB. Aus dem vorliegenden Versuch geht hervor, dass die aus $C R$ extrahierte Saponin- und Restfraktion und deren Subfraktionen S1 und R2 im Vergleich zur Kontrollgruppe eine signifikante Zunahme der Skelettmuskelfaserfläche bewirken (Abb. 3.3 und Abb. 3.4). 
Die stärkste Zunahme zeigte sich unter dem Einfluss der Saponinfraktion, dicht gefolgt von der S1-Subfraktion. Unter dem Einfluss der anderen Subfraktionen zeigten sich im Vergleich zur Kontrollgruppe keine signifikant größeren Skelettmuskelfaserflächen. Somit lässt sich folgern, dass die Saponin-, die Rest-, die S1- und die S2-Fraktion zu einer Hypertrophie der Muskulatur führen und somit muskelanabol wirken. Diese Hypertrophie wird durch die Querschnittsvergrößerung der kontraktilen Eiweißfäden in den Myofibrillen und deren zahlenmäßige Zunahme in den Muskelfasern hervorgerufen (Hoppele und Billeter 2003; Speckmann et al. 2008).

Bei konstanter Anzahl der Skelettmuskelfasern bewirkt eine Vergrößerung der einzelnen Skelettmuskelfaserflächen eine Vergrößerung der Gesamtquerschnittsfläche des Muskels. Diese Veränderung lässt eine Stärkung der Muskelkraft und Unterstützung der Funktion des muskuloskelettalen Systems vermuten.

Die Muskelschwäche des Alters beruht im Gegensatz hierzu auf einer Hypotrophie und somit Verkleinerung der Querschnittsfläche der einzelnen Muskelfasern (Saltin und Helge 2000).

Der Begriff Sarkopenie ist zur Zeit für tierexperimentelle Versuche nicht genau definiert, deshalb kann der Begriff bei unserem Versuchsaufbau nur bedingt Anwendung finden. Jedoch ließ sich in diesem Versuch eine östrogenmangelbedingte Abnahme der Skelettmuskelfaserfläche der Kontrollgruppe verzeichnen, welche die geringsten Skelettmuskelfaserflächen aufweist. Eine Untersuchung mit nicht ovx Tieren als Kontrollgruppe könnte hier weitere Ergebnisse liefern. Manifester Östrogenmangel als Ursache für die Entstehung einer Sarkopenie, einer Atrophie der Muskulatur, ist beim Menschen erwiesen (Sirola und Rikkonen 2005). Ferner ist bei den Ergebnissen zu bedenken, dass auch die Körpergewichte und das Wachstum der Tiere möglicherweise Einfluss auf die Muskelmasse genommen haben.

\subsubsection{EZM Skelettmuskulatur}

Der Anteil der EZM der Skelettmuskulatur bestimmt die Dichte der Muskulatur. Je höher diese Dichte ist, desto reißfester und zugelastischer ist der Muskel und umso stabiler ist auch die Verbindung zwischen Muskulatur, Sehnen und Knochen.

In unserem Versuch ergab sich eine im Vergleich zur Kontrollgruppe signifikante Zunahme der EZM unter dem Einfluss der Saponinfraktion, der S1-, der R1-Fraktion und Estradiolbenzoat. Die größte Zunahme der EZM zeigte sich unter dem Einfluss von Estradiolbenzoat, dicht gefolgt von der Saponinfraktion. Somit lässt sich folgern, dass die Saponin-, die S1- und die R1-Fraktion anabol auf die EZM wirken. Es stellt sich die Frage, auf welcher Veränderung der Zusammensetzung der EZM diese Zunahme beruht. 
Über den Einfluss von Östrogenen auf die EZM anderer Organe, wie beispielsweise Haut oder glatte Muskulatur, liegen bereits einige Studien vor, nicht jedoch über deren Wirkungen auf die EZM der Herz- und Skelettmuskulatur.

Man könnte vermuten, dass die EZM der Kontrollgruppe sich durch die klimakteriell bedingte katabole Stoffwechsellage verringert hat. Die Vermutung, dass die EZM der Kontrollgruppe sich durch die katabole Stoffwechsellage verringert hat, sollte durch eine weitere Studie mit nicht ovx Tieren in der Kontrollgruppe überprüft werden.

Obwohl der Mechanismus des Kollagenstoffwechsels der EZM noch nicht gänzlich geklärt ist, ließ sich in verschiedenen Studien nachweisen, dass während des Muskelwachstums auch die Kollagensynthese adaptiv ansteigt. Diese gesteigerte Kollagensynthese kann sowohl auf einer größeren Anzahl an Fibroblasten als auch auf einer gesteigerten Produktion an Kollagen pro Fibroblastenzelle beruhen (Laurent et al. 1985). Jedoch wirken die Bestandteile von $C R$, wie aus den Ergebnissen dieses Versuches hervorgeht, nicht gleichmäßig auf die Skelettmuskelfaserfläche und die EZM der Skelettmuskulatur. Die einzelnen Fraktionen und Subfraktionen bewirken in unterschiedlichem Umfang eine Zunahme von Skelettmuskelfaserfläche und/ oder EZM der Skelettmuskulatur.

\subsubsection{Herz}

\subsubsection{Kardiomyozytenfläche}

Die Kardiomyozytenfläche sagt etwas über die Dicke der einzelnen Herzmuskelzellen und somit die Querschnittsfläche des Herzens aus. Wie in der Skelettmuskulatur lässt sich von ihr indirekt auf die Pumpkraft des Herzmuskels schließen. Je größer die Kardiomyozytenfläche der Herzmuskelzellen, desto bessere Pumpkraft besitzt das Herz, um die verschiedenen Organe unseres Körpers adäquat zu versorgen. Einige Studien assoziieren mit kardialer Hypertrophie und Bluthochdruck eine erhöhte kardiovaskuläre Mortalität (Jazbutyte et al. 2006). Die entsprechende Literatur nennt keine Maximalwerte, bis zu welchem Umfang eine Hypertrophie der einzelnen Kardiomyozyten positiv für die Funktion des Myokards ist (Jazbutyte et al. 2006).

Die Anwendung von $C R$ zur Stärkung der Herzfunktion durch ausschließlich naturheilkundlich orientierte Bevölkerungsgruppen schon vor langer Zeit deutet bereits auf positive Effekte unserer Testsubstanz auf die Herzmuskulatur hin.

Unser Versuch zeigte eine signifikante Zunahme der Kardiomyozytenfläche unter dem Einfluss der Saponin-, der Restfraktion und all ihrer Subfraktionen im Vergleich zur Kontrollgruppe. Zudem ergab sich auch eine signifikante Zunahme der Kardiomyozytenfläche unter dem Einfluss von Estradiolbenzoat. In verschiedenen Studien konnte sowohl ein anaboler als auch ein kataboler Effekt der Östrogene auf die 
Herzmuskulatur beobachtet werden (Jazbutyte et al. 2006). Östrogene senken das LDLCholesterin und dienen somit der Prävention von kardiovaskulären atherosklerotischen Erkrankungen (Kuhl 1996; Karck et al. 1999; Windler 2000). Bei einer Steigerung des Herzzeitvolumens wirken sie negativ chronotrop und mindern so den peripheren arteriellen Widerstand, auf dem weitere protektive Effekte bei kardiovaskulären Erkrankungen beruhen (Kuhl 1996; Gips 2000).

Zur größten Zunahme kam es unter dem Einfluss der Subfraktionen S1 und R3. Somit lässt sich folgern, dass die Saponin-, die Restfraktion und all ihre Subfraktionen myokardial anabol wirken.

Vergleichbare Studien zum Effekt von $C R$ auf die Kardiomyozytenfläche sind in der Literatur nicht bekannt. Auch hier ist kritisch anzumerken, dass Körpergewichte und Wachstum der Tiere u. U. Einfluss auf die Veränderung der Herzmuskelmasse haben können.

\subsubsection{EZM Herz}

Die EZM des Myokards spielt eine entscheidende Rolle für die Integrität und Funktion des Herzens. Sie verbindet die einzelnen Myozyten zu einer strukturellen und funktionellen Einheit (Pauschinger et al. 2002).

Es ist auch hier zu vermuten, dass die EZM der Kontrollgruppe sich aufgrund der generell katabolen Stoffwechsellage des Klimakteriums verringert hat. Die Verifizierung dieser Annahme bedarf jedoch weiterer Untersuchungen, allerdings mit einer Vergleichsgruppe nicht ovx Tiere.

In unserem Versuch zeigte sich unter dem Einfluss von Estradiolbenzoat, der Saponin- der S1-, der Rest- und der R3-Fraktion eine signifikante Zunahme der EZM im Vergleich zur Kontrollgruppe. Der größte Zuwachs an EZM wurde unter dem Einfluss der Saponin- und der R3-Fraktion registriert.

Es liegt nahe, dass die EZM der Kontrollgruppe sich aufgrund der generellen katabolen Stoffwechsellage des Klimakteriums verringert hat. Weitere Untersuchungen mit nicht ovx Tieren als Vergleichsgruppe könnten zur Klärung dieser Fragestellung beitragen.

Es stellt sich wiederum die Frage, auf welcher Veränderung der Zusammensetzung der EZM diese Zunahme beruht. Inwieweit CR eine andere oder vergleichbare Wirkung wie die von uns untersuchten Fraktionen und Subfraktionen auf die EZM des Myokards hat, ist nicht zu beurteilen, da vergleichbare Studien zu CR nicht existieren.

Ferner ist auch bei diesen Ergebnissen zu bedenken, dass die Körpergewichte und das Wachstum der Tiere möglicherweise Einfluss auf die EZM der Herzmuskulatur genommen haben. 


\subsubsection{Vergleich von Herz- und Skelettmuskulatur}

Zur Veranschaulichung der Ergebnisse und zum gezielten Vergleich der verschiedenen Messungen, insbesondere der Herz- und Skelettmuskulatur miteinander, dient die folgende Tab 4.1. Die hier genannten signifikanten Zunahmen beziehen sich jeweils auf den Vergleich mit den Werten der Kontrollgruppe.

\begin{tabular}{|c|l|l|l|l|}
\hline Gruppe & $\begin{array}{l}\text { Signifikante } \\
\text { Zunahme } \\
\text { Skelettmuskel- } \\
\text { faserfläche }\end{array}$ & $\begin{array}{l}\text { Signifikante } \\
\text { Zunahme } \\
\text { Herzmuskel- } \\
\text { faserfläche }\end{array}$ & $\begin{array}{l}\text { Signifikante Zunahme der } \\
\text { EZM, bezogen auf die } \\
\text { Skelettmuskelfaserfläche }\end{array}$ & $\begin{array}{l}\text { Signifikante Zunahme der } \\
\text { EZM, bezogen auf die } \\
\text { Herzmuskelfaserfläche }\end{array}$ \\
\hline EB & $\mathrm{X}$ & $\mathrm{X}$ & $\mathrm{X}$ & $\mathrm{X}$ \\
\hline Sap & $\mathrm{X}$ & $\mathrm{X}$ & OF & $\mathrm{X}$ \\
\hline Rest & $\mathrm{X}$ & $\mathrm{X}$ & $\mathrm{X}$ & $\mathrm{X}$ \\
\hline S1 & $\mathrm{X}$ & $\mathrm{X}$ & $\mathrm{X}$ & OF \\
\hline S2 & OF & $\mathrm{X}$ & OF & OF \\
\hline S3 & OF & $\mathrm{X}$ & $\mathrm{X}$ & OF \\
\hline R1 & OF & $\mathrm{X}$ & OF & OF \\
\hline R2 & $\mathrm{X}$ & $\mathrm{X}$ & OF & $\mathrm{X}$ \\
\hline R3 & OF & & & \\
\hline
\end{tabular}

$\mathrm{X}=$ signifikant im Vergleich zur Kontrolle

$\mathrm{OF}=$ ohne Effekt im Vergleich zur Kontrolle

\section{Tab. 4.1 Vergleich der Versuchsreihe zur Herz- und Skelettmuskultur}

Aus der vorstehenden Tabelle wird ersichtlich, dass unter dem Einfluss der EB-Gruppe, der Saponinfraktion und der S1-Subfraktion sowohl die Myozytenflächen als auch die Anteile der EZM, der Skelett- und Herzmuskulatur eine signifikante Zunahme im Vergleich zur Kontrollgruppe verzeichnen. Ableiten lässt sich ebenfalls, dass die Subfraktionen der Saponin- und Restfraktion keine einheitliche Wirkung auf Herz- und Skelettmuskulatur zeigen. Somit lässt sich folgern, dass die Bestandteile von $C R$ ihre Wirkung unterschiedlich in Herz- und Skelettmuskulatur entfalten, da nicht dieselben Fraktionen und Subfraktionen die jeweils stärkste anabole Wirkung auf Kardiomyozyten- und Skelettmuskelfaserfläche und auf die EZM beider Gewebe mit sich bringen.

Nahezu regelmäßig erweist sich vor allem die Actein und Deoxyactein enthaltende S1Fraktion als wirksamste Substanzgruppe (Abb. 1.2). 
Durch die acteininduzierte Hemmung der Biosynthese der freien Fettsäuren und des Cholesterols resultieren positive Wirkungen auf den Fettstoffwechsel. Ebenso lassen sich positive Wirkungen auf das Herzkreislaufsystem vermuten (Einbold et al. 2011). Actein bewirkt eine periphere Vasodilatation und trägt so zu einer Blutdrucksenkung bei, was in Konsequenz positive Auswirkungen auf das Herzkreislaufsystem hat (Gardiner 2001). Auch sind inhibitorische Eigenschaften des Acteins und Deoxyacteins auf die Rezeptoren des Mammakarzinoms und des Leberkarzinoms nachgewiesen (Einbold et al. 2011; Bone und Mills 2013). Andere Studien belegen, dass Actein keine toxischen Wirkungen auf Herz oder Bewegungsapparat aufweist (Herbalist et al. 2002; Bone und Mills 2013). Unter den Triterpenglykosiden, zu denen u.a. Actein gehört, besitzen einige Substanzen GABAerge Wirkung. Durch die Modulation von GABA Typ A- Rezeptoren bewirken Teile von CR eine Linderung klimakterischer Beschwerden (Cicek et al. 2010). GABA-Rezeptoren finden sich vorwiegend in Gehirn und Rückenmark. Sie dienen in diesem Kontext unter anderem der Reflexverschaltung und der Koordination von Bewegungsabläufen. Dieses Thema war bereits Gegenstand anderer Dissertationen. 


\section{$5 \quad$ Zusammenfassung und Ausblick}

Im Rahmen des demographischen Wandels kommt es zu einem kontinuierlichen Anstieg des Anteils postmenopausaler Frauen an der Weltbevölkerung, so dass die Therapie postmenopausaler Erkrankungen zu einem wichtigen Thema der ärztlichen Behandlung geworden ist.

Seit Beginn des 21. Jahrhunderts werden hinsichtlich der klinischen Wirksamkeit und der Sicherheit der Hormonersatztherapie vermehrt Bedenken im Hinblick auf das erhöhte Risiko für das kardiovaskuläre System und Brustkrebs geäußert. Aus diesem Grund rücken alternative Therapieansätze verstärkt in den Mittelpunkt der Forschung (Rabe et al. 2004). In unterschiedlichen Projekten hat sich hierbei $C R$ als effektives, in der klinischen Praxis anwendbares Medikament gezeigt (Osmers et al. 2005). Die vorliegende Dissertation setzte sich mit der Wirkung von Subfraktionen unserer Testsubstanz $C R$ auf die klimakterisch bedingten Veränderungen bzw. Erkrankungen der quergestreiften Muskulatur und somit der Skelett- und der Herzmuskulatur auseinander.

Vor diesem Hintergrund wurden 100 weibliche, zuvor ovx Sprague-Dawley-Ratten (Fa. Harlan-Winkelmann, Borchen) in 10 Gruppen unterteilt. Die ovx Ratte ist heutzutage ein anerkanntes und häufig angewandtes Modell in der Endokrinologie (Bellino 2000).

Den Tieren wurden über einen Zeitraum von 4 Wochen die verschiedenen Substanzen von CR (Saponin-, S1-, S2-, S3-Fraktion und Rest-, R1-, R2- und R3-Fraktion) oder EB verabreicht. Über denselben Zeitraum wurde eine Kontrollgruppe mit sojafreiem Futter versorgt. Mittels histologischer Untersuchung der Herz- und Skelettmuskulatur wurden die Auswirkungen von EB und den verschiedenen Fraktionen und Subfraktionen aus $C R$ ermittelt und untereinander und mit den Ergebnissen der Kontrollgruppe verglichen.

Unter dem Einfluss von EB, der Saponinfraktion und der S1-Subfraktion verzeichneten sowohl die Myozytenflächen als auch die Anteile der EZM der Skelett- und Herzmuskulatur eine signifikante Zunahme im Vergleich zur Kontrollgruppe. Ableiten lässt sich ebenfalls, dass die Subfraktionen der Saponin- und Restfraktion keine gleichmäßige Wirkung auf die strukturellen Bestandteile von Herz- und Skelettmuskulatur zeigen. Es lässt sich folgern, dass einzelne Bestandteile von $C R$ unterschiedliche Wirkungen in Herz- und Skelettmuskulatur entfalten, da nicht dieselben Fraktionen und Subfraktionen die jeweils stärkste anabole Wirkung auf Kardiomyozyten- und Skelettmuskelfaserfläche und auf die EZM beider Gewebe mit sich bringen. Die Ergebnisse sprechen dafür, dass bestimmte Subfraktionen von $C R$ anabol auf die Skelettmuskelfaser- und Kardiomyozytenfläche und die EZM beider Gewebe wirken. Nahezu regelmäßig erweist sich die vor allem Actein und 
Deoxyactein enthaltende S1-Fraktion als wirksamste Substanzgruppe (Abb. 1.2).

In Zukunft könnten die jeweiligen Subfraktionen gezielt, wie beispielsweise die wirkungsstarke S1-Fraktion, sowohl zur Stärkung der Muskulatur bei Sarkopenie als auch zur Stärkung der Herzmuskulatur eingesetzt werden.

Auf Grundlage unserer Ergebnisse können weitere Folgeversuche die genauere Analyse der EZM-Zunahme unter dem Einfluss der verschiedenen Substanzen aus $C R$ liefern. Hierzu stellt sich die Frage welche Unterstrukturen der EZM in Herz- und Skelettmuskulatur eine Zunahme erfahren haben. Ein identischer Versuchsablauf, allerdings mit nicht ovx Tieren in einer Vergleichsgruppe, könnte eine vergleichende Analyse der $\mathrm{Zu}$ - und Abnahme der Muskelfaserflächen und der EZM in Herz- und Skelettmuskulatur ermöglichen. Zudem wäre ein Vergleich mit einer Gruppe, welche die vollständige Substanz CR verabreicht bekommt, von Nutzen.

Die Wirkungen von $C R$ sind noch Gegenstand der aktuellen Forschung. Es bleiben noch viele, anhand der vorliegenden Forschungsresultate unbeantwortete Fragen. Ziel weiterer Untersuchungen sollte sein, welche Subsubstanzen der Subfraktionen aus der Abb. 1.2 für die Veränderungen der Skelettmuskelfaserfläche, der Kardiomyozytenfläche und der EZM beider Gewebe verantwortlich sind und über welchen Wirkmechanismus und welche Rezeptoren diese ihre Wirkung entfalten. Es erscheint sinnvoll, unterschiedliche Konzentrationen und auch die Gabe des Präparates über unterschiedliche Zeiträume zu untersuchen. Ein weiteres Ziel der Forschung müsste darüber hinaus die Ermittlung der Kombination der jeweiligen Fraktionen und Subfraktionen sein, um eine bestmögliche osteoprotektive und anabole Wirkung auf Herz- und Skelettmuskulatur und den Knochen zur Linderung oder Beseitigung klimakterischer Beschwerden zu entfalten. Die im Tierversuch gefundenen optimalen Dosierungen bedürfen darüber hinaus noch der Überprüfung hinsichtlich ihrer Übertragbarkeit auf den menschlichen Organismus. 


\section{$6 \quad$ Anhang}

Die Reihenfolge der Abbildungen und Texte im Anhang orientiert sich an deren Reihenfolge dieser Dissertation.

\subsection{Anhang Einleitung}

\section{A Klimadynon (BNO 1055)}

In dieser Dissertation fand das Produkt Klimadynon der Firma Bionorica Verwendung. Es besteht aus dem Spezialextrakt BNO 1055. Der Gebrauchsinformation für den Anwender sind die folgenden Informationen zu entnehmen: Die Indikation zur Anwendung von Klimadynon besteht in der Besserung von Wechseljahresbeschwerden wie z.B. Hitzewallungen und übermäßigen Schweißausbrüchen. Die Filmtabletten des Klimadynons setzen sich aus 2,8 mg Spezialtrockenextrakt (BNO 1055), CalciumhydrogenphosphatDihydrat, Eudragit RL 30 D, Kartoffelstärke, Lactose-Monohydrat, Macrogol 6000, Magnesiumstearat, Talkum und den Farbstoffen E 171 und E 172 zusammen. Es sind Packungen mit 60 oder 90 Filmtabletten erhältlich. Mögliche Nebenwirkungen sind u.a. Leberschädigungen, Hautreaktionen und Magen-Darm-Beschwerden. Die Häufigkeit dieser möglichen Nebenwirkungen ist auf der Grundlage der verfügbaren Daten nicht abschätzbar. Die Anwendung von Klimadynon in der Schwangerschaft und Stillzeit wird wegen nicht vorliegender Untersuchungen nicht empfohlen. 


\subsection{Anhang Material und Methoden}

\begin{tabular}{|l|l|}
\hline Lösung & Einwirkdauer \\
\hline $50 \%$ iger Alkohol & 1 Stunde \\
\hline $75 \%$ iger Alkohol & 1 Stunde 20 Minuten \\
\hline $75 \%$ iger Alkohol & 1 Stunde 20 Minuten \\
\hline $96 \%$ Stunder Alkohol 20 Minuten \\
\hline $96 \%$ iger Alkohol & 1 Stunde 20 Minuten \\
\hline $100 \%$ iger Alkohol & 1 Stunde 20 Minuten \\
\hline $100 \%$ iger Alkohol & 1 Stunde 20 Minuten \\
\hline $100 \%$ iger Alkohol & 1 Stunde 20 Minuten \\
\hline Xylol & 1 Stunde 20 Minuten \\
\hline Xylol & 1 Stunde 20 Minuten \\
\hline Paraffin & 1 Stunde \\
\hline Paraffin & 1 Stunde \\
\hline
\end{tabular}

(Romeis 2010)

Tab. 2.2 Paraffineinbettung: Konzentrationen der Lösungen mit jeweiligen Einwirkzeiten

\section{A HE-Färbung}

Bei dieser Färbemethode wird zunächst mittels Xylol und Lösungen mit absteigenden Alkoholgehalten das Paraffin der Objektträger entfernt. Anschließend werden die Organe mit Hämatoxylin und Eosin angefärbt.

Die genaue Einwirkzeit dieser beiden Hauptkomponenten für eine optimale Färbung variiert mit der Zusammensetzung der Lösungen. Sie muss bei jedem Neuansetzen der Farbe durch Probefärbungsdurchläufe ermittelt werden.

Das Hämatoxylin, eine Farbstoffvorstufe, muss generell zuerst durch chemische oder künstliche Oxidation in Hämatein überführt werden. Hämatein bildet mit Aluminiumionen den notwendigen Farbstoff Hämalaun. Bei der Färbung wurde eine Fertiglösung des Hämalauns der Firma Merck verwendet (Mayers Hämalaunlösung, 1.09249.0500). Vor Gebrauch musste dieses jedoch filtriert werden. Das basische, positiv geladene Hämalaun färbt das Chromatin der Zellkerne blau, indem es mit den negativ geladenen Phosphatgruppen der Nucleinsäuren 
eine schwerlösliche Verbindung eingeht. Das Hämalaun liegt durch die Zitronensäure in saurer Lösung vor. So werden die negativ geladenen Carboxylgruppen im Zytoplasma abgesättigt. Dadurch kommt es zu einer selektiven Kernfärbung. Die meisten Proteine des Zytoplasmas sind negativ geladen, da sie einen niedrigen isoelektrischen Punkt aufweisen. Die positiv geladenen Wasserstoffionen der sauren Lösung geben dem Zytoplasma positive Ladungen. So kann sich das negativ geladene Eosin (Tetrabrom-Flourescein-Natrium) in leicht saurer Lösung an die unter dem Einfluss der Azidität positiv geladenen Proteine und die interzellulären Strukturen, wie z.B.Kollagen, anlagern und sie rot färben.

(Mulisch und Welsch 2010)

Die Eosinlösung wurde von Frau H. Brüggemann-Meyer (MTA) angesetzt. Es wurden $1 \mathrm{~g}$ Eosinpulver mit 50ml 70\%tigem Ethanol und 50ml Aqua dest mittels eines Magnetrührers vermischt bis sich alles in Lösung befand. Die so entstandene Stocklösung wurde zuletzt im Verhältnis 2:1 (Stocklösung: Aqua dest) mit Aqua dest verdünnt.

Nach der Färbung der Präparate mit Hämatoxylin und Eosin folgt eine aufsteigende Alkoholreihe. Die Färbung endet mit drei Xylolwasserbädern in Folge, die der Stabilisierung der Präparate dienen. Anschließend wurden die Objektträger mit einer Pinzette aus dem Xylolbad vorsichtig herausgenommen und die Rückseite des Objektträgers abgetrocknet. Zum Schluss wurden auf den Objektträgern noch Menzel-Deckgläser mithilfe von Klebstoff (Depex) zum Schutz der Präparate fixiert. 


\begin{tabular}{|l|l|}
\hline Lösungsbäder & Einwirkdauer \\
\hline Xylol & $10 \mathrm{~min}$ \\
\hline Xylol & $10 \mathrm{~min}$ \\
\hline Xylol & $10 \mathrm{~min}$ \\
\hline Ethanol 100\% & $2 \mathrm{~min}$ \\
\hline Ethanol 100\% & $2 \mathrm{~min}$ \\
\hline Ethanol 100\% & $2 \mathrm{~min}$ \\
\hline Ethanol 96\% & $2 \mathrm{~min}$ \\
\hline Ethanol 96\% & $2 \mathrm{~min}$ \\
\hline Ethanol $75 \%$ & $2 \mathrm{~min}$ \\
\hline Aquadest & $2 \mathrm{~min}$ \\
\hline Hämatoxylin & $40 \mathrm{sec}$ \\
\hline Leitungswasser & $10 \mathrm{~min}$ \\
\hline Aquadest & $1 \mathrm{~min}$ \\
\hline Eosin & $75 \mathrm{sec}$ \\
\hline Aquadest & $8 \mathrm{Mal} \mathrm{Eintauchen}$ \\
\hline Ethanol $75 \%$ & $30 \mathrm{sec}$ \\
\hline Ethanol 96\% & $30 \mathrm{sec}$ \\
\hline Ethanol 96\% & $30 \mathrm{sec}$ \\
\hline Ethanol 100\% & $1 \mathrm{~min}$ \\
\hline Ethanol 100\% & $1 \mathrm{~min}$ \\
\hline Ethanol 100\% & $2 \mathrm{~min}$ \\
\hline Xylol & $5 \mathrm{~min}$ \\
\hline Xylol & $5 \mathrm{~min}$ \\
\hline Xylol & $5 \mathrm{~min}$ \\
\hline Romein & \\
\hline
\end{tabular}

(Romeis 2010)

Tab. 2.3 HE-Färbung

2.B Van-Gieson-Färbung in Kombination mit der Resorcinfuchsinfärbung nach Weigert

Als erstes wurden die Präparate mittels einer absteigenden Alkoholreihe entparaffiniert. Anschließend wurden die elastischen Fasern mithilfe einer Resorcinfuchsinlösung regressiv angefärbt. Die aus Elastin und Fibrillin bestehenden elastischen Fasern gehören zu den strukturdichtesten Anteilen im Körper. Aufgrund ihrer stark sauren Eigenschaften binden sie über Prinzipien der Grenzflächenadsorption und der Elektropolarität aus einer ethanolischen stark sauren Lösung den fein dispersen Beizen-Farbstoff Resorcinfuchsin. Laut der Legende dieser Färbung erscheinen dadurch die elastischen Fasern violett auf rosa Grund. Anschließend wurden die Präparate mit Aqua dest ausgewaschen und mit 96prozentigem 
Alkohol differenziert und wiederum mittels Aqua dest abgespült. Zur daraufhin folgenden Kernfärbung wurde Eisenhämatoxylin verwendet, welches nicht durch die im Verlauf folgende aggressive Pikrinsäure gelöst werden kann. Die Kerne erhalten dadurch eine blauschwarz-braune Farbe. Im Folgenden wurden die Präparate unter laufendem Leitungswasser bewässert und mit Aqua dest abgespült. Die letzte Färbung war die simultane aus zwei Farbstoffen bestehende Pikrofuchsinfärbung nach Van Gieson. Die beiden Farbstoffe dieses Gemisches, die Pikrinsäure und das Säurefuchsin unterscheiden sich in ihrer Dispersität, Diffusibilität und Konzentration. Während der Färbezeit diffundiert die feindisperse, hochkonzentrierte Pikrinsäure in alle Strukturen des Gewebes. Diese nehmen dadurch eine gelbe Farbe an. In die sehr weiten Strukturlücken des kollagenen Bindegewebes dringt während dieser Zeit das grobdisperse, schwach konzentrierte Säurefuchsin ein und überlagert in diesen Bereichen die Pikrinsäure. In diesem Augenblick muss die Färbung gestoppt werden, da ansonsten auch das Zytoplasma rote Farbe annimmt.

(Romeis 2010)

Die genauen Einwirkzeiten der Färbungen sind der folgenden Tabelle Abb. 2.4 ebenfalls im Anhang zu entnehmen. 


\begin{tabular}{|c|c|c|}
\hline Vorgang & Lösungsbäder & Einwirkdauer \\
\hline \multirow[t]{6}{*}{ Entparaffinieren } & Ethanol $100 \%$ & $2 \min$ \\
\hline & Ethanol $100 \%$ & $2 \min$ \\
\hline & Ethanol $100 \%$ & $2 \min$ \\
\hline & Ethanol $96 \%$ & $2 \min$ \\
\hline & Ethanol $96 \%$ & $2 \min$ \\
\hline & Ethanol $75 \%$ & $2 \min$ \\
\hline \multirow[t]{2}{*}{ Elastika-Färbung } & 1:1 Resorcinfuchsin + HCL-Alkohol & $30-45 \mathrm{~min}$ \\
\hline & Aqua dest & abspülen \\
\hline \multirow[t]{2}{*}{ Differenzieren } & $100 \mathrm{ml}$ Ethanol $96 \%+1 \mathrm{ml} \mathrm{HCL} 32 \%$ & kurz \\
\hline & Aqua dest & abspülen \\
\hline \multirow{3}{*}{$\begin{array}{l}\text { Eisenhämatoxylin- } \\
\text { Weigert }\end{array}$} & 2 fertige Lösungen 1:1 mischen & $5-6-\min$ \\
\hline & Wässern unter Leitungswasser & Ca. $10 \mathrm{~min}$ \\
\hline & Aqua dest & $1 \mathrm{~min}$ \\
\hline \multirow[t]{10}{*}{ Pikrofuchsin v. Gieson } & Fertige Lösung & Ca. 3min \\
\hline & Aqua dest & abspülen \\
\hline & Ethanol $96 \%$ & $2 \mathrm{~min}$ \\
\hline & Ethanol $96 \%$ & $2 \mathrm{~min}$ \\
\hline & Ethanol $100 \%$ & $2 \mathrm{~min}$ \\
\hline & Ethanol $100 \%$ & $2 \mathrm{~min}$ \\
\hline & Ethanol $100 \%$ & $2 \min$ \\
\hline & Xylol & $5 \mathrm{~min}$ \\
\hline & Xylol & $5 \mathrm{~min}$ \\
\hline & Xylol & $5 \mathrm{~min}$ \\
\hline
\end{tabular}

(Romeis 2010)

Tab. 2.4 Van-Gieson-Färbung in Kombination mit der Resorcinfuchsinfärbung nach Weigert 


\section{$7 \quad$ Literaturverzeichnis}

Aumüller G, Aust G, Doll A, Engele J, Kirsch J, Mense S, Reißig D, Salvetter J, Schmidt W, Schmitz F, Schulte E, Spanel-Borowski K, Wolff W, Wurzinger L, Zilch H-G: Duale Reihe Anatomie, 1. Auflage, Georg Thieme Verlag, Stuttgart 2007, 363, 398, 403

Bailey AJ, Shellswell GB, Duance VC (1979): Identification and change of collagen types in differentiating myoblasts and developing chick muscle. Nature $\underline{278}, 67-69$

Baumgartner RN, Koehler KM, Gallagher D, Romero L, Heymsfield SB, Ross RR, Garry PJ, Lindeman RD (1998): Epidemiology of Sarcopenia among the Elderly in New Mexico. Am J Epidemiol 147, 755

Bellino FL (2000): Nonprimate animal models of menopause: workshop report. Menopause $\underline{7}, 14-24$

Beral V, Million Women Study Collaborators (2003): Breast cancer and hormonereplacement-therapy in the Million Woman Study. Lancet 362(9390), 419-427

Berk BC, Fujiwara K, Lehoux S (2007): ECM remodeling in hypertensive heart disease. JCI $\underline{117}, 569-570$

Bloch W, Schmidt A: Sport und freie Radikale. In: Blickpunkt der Mann 3/2004. Wissenschaftliches Journal für Männergesundheit. Krause \& Pachernegg GmbH-Verlag für Medizin und Wirtschaft, Gablitz 2004, 16,17

Boblitz N: Therapie klimakterischer Beschwerden mit Cimicifuga racemosa: Erkenntnisse zu Wirkung und Wirksamkeit. In: Journal für Menopause. Krause \& Pachernegg GmbH-Verlag für Medizin und Wirtschaft, 2002(3), 21-25

Bone K, Mills S: Principals and Practice of Phytotherapy. Elsevier-Verlag, 2. Auflage; 2013, 430-434

Borrelli F, Edzard E (2002): Cimicifuga racemosa: a systematic review of it's clinical efficacy. Eur J Clin Pharmacol $\underline{58}$, Springer-Verlag, 235

Brown M (2008): Skeletal muscle and bone: effect of sex steroids and aging. Adv Physiol Educ. $32(2), 120-126$

Burton LA, Sumukadas D (2010): Optimal management of sarcopenia. J Clin Interv Aging $\underline{5}$, 
Cicek SS, Khom S, Taferner B, Hering S, Stuppner H (2010): Bioactivity-Guided Isolation of GABA A Receptor Modulating Constituents from the Rhizomes of Actaea racemosa. J Nat Prod $\underline{73}(12)$, 2024- 2028

Eghbali M, Tomek R, Sukhatme VP, Woods C, Bhambi B (1991): Differential Effects of Transforming Growth Factor $\beta 1$ and Phorbol Myristate Acetate on Cardiac Fibroblasts. JAHA, 483-484

Einbold LS, Soffritti M, Eposti DD, Wu H, Tibaldi E, Lauriola M, He K, Park T, Su T, Huggins L, Wang X, Roller M, Brennan R (2011): Pharmacological mechanisms of black cohosh in Sprague-Dawley rats. Elsevier-Verlag, 461-468

Erdmann E, Schneider CA: Klinische Kardiologie, Kardiovaskuläre Risikofaktoren und deren therapeutische Beeinflussung, 8. Auflage, Springer Medizin Verlag, Berlin 2008, 1

Evans WJ (2010): Skeletal Muscle loss: cachexia, sarcopenia and inacticity. Am J Clin Nutr $\underline{91}(4), 1123-1127$

Faulds MH, Zhao C, Dahlman-Wright K, Gustafsson J-A (2012): The diversity of sex steroid action: regulation of metabolismby estrogen signaling. J Endokrinol 212, 3-12

Feinstein B, Lindegard B, Nyman E, Wohlfart G(1955): Morphologic studies of motor units in normal human muscles. Acta Anat $\underline{23}, 127-142$

Gardiner P (2001): Black Cohosh (CR), Longwood Herbal Task Force $\underline{5}$

Gips H: Neurobiologische, kardiovaskuläre und kardiale Wirkung natürlicher Östrogene. Gießener Gynäkologische Fortbildung. 21. Auflage; Springer-Verlag 2000, 145-150

Grady D, Applegate W, Bush T, Furberg C, Riggs B, Hulley SB (1998): Heart and Estrogen/progestin Replacement Study (HERS): design, methods, and baseline characteristics. 19 14$), 314-335$

Herbalist RU, Graff A, Swisher D (2002): Black Cohosh Rhizome Actaea racemosa L.syn. Cimicifuga racemosa (L.) Nutt, Standards of Analysis, Quality Control, and Therapeutics. Am Herb Pharm 34 (8), 1099-1101

Hoppeler H, Billeter R (2003): Struktur und Funktion der Skelettmuskulatur aus der Abteilung 
für Systematische Anatomie. Hans Huber Verlag, $\underline{60}$ (7), 363-370

Jazbutyte V, Hu K, Kruchten P, Bey E, Maier SKG, Fritzemeier KH, Prelle K, Hegele-Hartung C, Hartmann RW, Neyses L, Ertl G, Pelzer T (2006): Aging Reduces the Efficacy of estrogen Substitution to attenuate Cardiac Hypertrophy in Female Spontaneously Hypertensive Rats. JAHA, 583

Kalbe C, Mau M, Wollenhaupt K, Rehfeldt C (2007): Evidence for estrogen receptor alpha and beta expression in skeletal muscle of pigs. Histochem Cell Biol 127(1), 95-107

Kalu DN (1991): The ovariectomized rat model of postmenopausal bone loss. Bone Miner $\underline{15}, 175-191$

Karck U, Keck U, Karck M, Breckwoldt M (1999): Effect of Oestrogens on the Cardiovascular System. Aktuel Urol 30(2), 89-94

Karow T, Lang-Roth R: Allgemeine und spezielle Pharmakologie und Toxikologie. 20. Auflage; Verlag T. Karow, Pulheim 2011, 1078-1079

Kindermann M, Böhm M: Das Herz im Alter. In: Klinische Kardiologie, Hrsg. v. Erdmann E., 8. Auflage; Springer Medizin Verlag, Heidelberg 2011, 481-490

Kjaer M (2004): Role of Extracellular Matrix in Adaption of Tendon and Skeletal Muscle to Mechanical Loading. Physiol. Rev. $\underline{84(2)}, 649-698$

Kleine-Gunk B: Das Frauen-Hormone-Buch. Trias-Verlag, Stuttgart 2009, 20

Krinke GJ: The laboratory rat. handbook of experimental animals. Academic Press, London 2000

Kuhl H: Kardiovaskuläre Protektion durch Östrogen-/Gestagen-Substitution. In: Deutsches Ärzteblatt 93(17); Deutscher Ärzte Verlag, Köln 1996, 51-53

Kuhl H: Klimakterium, Postmenopause und Hormonsubstitution. 3. Auflage, UNI-Med Verlag AG, Bremen 2006, 12, 16, 134, 216, 219

Lang T, Streeper T, Cawthon P, Baldwin K, Taaffe DR, Harris TB (2010): Sarcopenia: etiology, clinical consequences, intervention and assessment. Osteoporosis Int 21, 543-559

Lapiere CM, Nusgens B, Pierard GE (1977): Interaction between collagen type I and type III 
in conditioning bundles organization. Connect. Tissue. Res. $\underline{5}(1), 21-29$

Laurent GJ, McAnulty RJ, Gibson J (1985): Changes in collagen synthesis and degradation during skeletal muscle growth. Am J Physiol 249(3), 352-355

Liske E (1998): Therapeutic Efficacy and Safety of Cimicifuga racemosa for Gynecologic Disorders. Adv Nat Ther 15(1), 46-49

Liu J, Burdette JE, Xu H, Gu C, van Breemen RB, Bhat KPL, Booth N, Constantinou Al, Pezzuto JM, Fong HHS, Farnsworth NR, Bolton JL (2001): Evaluation of estrogenic activity of plant extracts for the potential treatment of menopausal symptoms. J Agric Food Chem $\underline{49}(5), 2472-2479$

Lüllmann-Rauch R: Taschenlehrbuch Histologie. 2. Auflage, Georg Thieme Verlag, Stuttgart 2006, 115-122, 209, 210, 223-225

Luppa D (2001): Regulation of food intake and efficiency of energy utilization. KCS $\underline{2}$ (6), 114123

Maltais ML, Desroches J, Dionne IJ (2009): Changes in muscle mass and strength after menopause. JMNI $\underline{9}(4), 186-197$

Markworth P: Sportmedizin Physiologische Grundlagen, 19. Auflage, rororo-Verlag, Berlin $2005,15,61,62,64$

McCormick R (1999): Extracellular Modifications to Muscle Collagen: Implications for Meat Quality. Poultry Sci $\underline{78}$, 785-791

Möllenhoff H, Weiß M, Heseker H: Muskelkräftigung für Senioren. 1. Auflage, Behr's Verlag DE, Hamburg 2005, 13

Mulisch M, Welsch U: Romeis Mikroskopische Technik, 18. Auflage, Springer-Verlag, Berlin 2010, 214-216, 220, 221

Osmers R, Friede M, Liske E, Schnitker J, Freudenstein J, Henneicke von Zepelin H (2005): Efficacy and Safety of Isopropanolic Black Cohosh Extract for Climacteric Symptoms. ACOG $\underline{105}(5), 1073-1083$

Osses N, Brandan E (2001): ECM is required for skeletal muscle differentiation indepen- 
dently of muscle regulatory factor expression. Am J Physiol Cell Physiol 282, 383- 394

Pauschinger M, Chandrasekharan K, Li J, Schwimmbeck PL, Noutsias M, Schultheiss HP (2002): Remodeling der extrazellulären Matrix bei dilatativer Kardiomyopathie. Herz 27, 677682

Pelzer T, Shamim A, Neyses L(1996): Estrogen effects in the heart. Mol Cell Biochem 160$\underline{161}, 307-313$

Pollänen E, Sipila S, Alen M, Ronkainen P, Ankarberg-Lindgren C, Puolakka J, Suominen H, Hämäläinen E, Turpeinen U, Konttinen Y, Kovanen V (2011): Differential influence of peripheral and systemic sex steroids on skeletal muscle quality in pre- and postmenopausal women. Aging cell $\underline{10}, 651-653$

Pschyrembel W, Dornblüth O: Psychremble Klinisches Wörterbuch. 261. Auflage; De Gruyter, Berlin, New York, 2007

Rabe T, Bock K, Deckner C, Geisthövel F, Mueck AO (2004): Hormonersatztheraphie Nutzen und Risiken. J Reproduktionsmed Endokrinol 12(2), 77-81

Raloff J (1996): Muscle loss in the elderly finally gets some respect. science news $\underline{150}(6), 90$

Rassow J, Hauser K, Netzker R, Deutzmann R: Duale Reihe Biochemie, 1. Auflage, Georg Thieme Verlag KG, Berlin 2008, 604

Reiser K, McCormick RJ, Rucker RB (1992): Enzymatic and nonenzymatic cross-linking of collagen and elastin. J FASEB $\underline{6}, 2439-2449$

Rikkonen T, Sirola J, Saloovaara K, Tuppurainen M, Jurvelin JS, Honkanen R, Kröger H (2012): Muscle Strength and Body Composition Are Clinical Indicators of Osteoporosis.

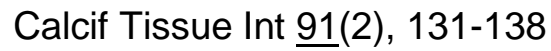

Rossmanith W G (1998): Endokrinologie des Klimakteriums. Der Gynäkologe 31(10), 822831

Roubenoff R (2001): Origins and clinical relevance of sarcopenia. Can J Appl Physiol 26(1), 78-89 
Saltin B, Helge JW (2000): Skeletal muscle, physical activity and health. Orthopädie $\underline{29}, 941$ 947

Saltiki K, Alevizaki M (2007): Coronary heart disease in postmenopausal women: The role of estrogens and their receptors. Hormones $\underline{6}(1), 9-24$

Seidlová-Wuttke D, Pitzel L, Thelen P, Wuttke W (2006): Inhibition of 5-alpha-reductase in the rat prostate by $C R$. Maturitas $\underline{55}, 75-82$

Seidlová-Wuttke D, Jarry H, Becker T, Christoffel V, Wuttke W(2003)b: Pharmacology of CR extract BNO 1055 in rats: bone, fat and uterus. Maturitas $\underline{44}(1), 31-38$

Seidlová-Wuttke D, Hesse O, Jarry H, Christoffel V, Spengler B, Becker T, Wuttke W (2003)a: Evidence for selective estrogen receptor modulator activity in a black cohosh extract: comparison with estradiol-17 $\beta$, Eur J Endokrinol 149(4), 351-362

Schünke M, Schulte E, Schumachen U: Prometheus- Lernatlas der Anatomie, 2. Auflage, Georg Thieme Verlag KG, Berlin 2007, 56

Schünke M, Schulte E, Schumacher U, Voll M, Wesker K: Prometheus-Lernatlas der Anatomie, Georg-Thieme Verlag KG, Berlin 2005, 102

Shumaker SA, Legault C, Rapp SR, Thal L, Wallace RB, Ockene JK, Hendrix SL, Jones BN, Assaf AR, Jackson RD, Kotchen JM, Wassertheil-Smoller S, Wactawski-Wende J (2003): Estrogen plus Progestin and the Incidence of Demetia and Mild Cognitive Impairment in postmenopausal woman: The Woman's Health Initiative Memory Study, JAMA, 289(20), 2651

Sirola J, Rikkonen T (2005): Muscle performance after the menopause. J Br Menopause Soc $\underline{11}, 45-50$

Sirola J, Kröger H (2011): Similarities in Acquired Factors related to postmenopausal Osteoporosis and Sarcopenian. J Osteoporos 2011, 1-3

Speckmann E-J, Hescheler J, Rüdiger K: Physiologie. 5. Auflage, Urban und Fischer, München 2008, 174-195, 389, 392

Stammel HJ: Die Apotheke Manitous - Das Heilwissen der Indianer. Rowohlt Verlag, Reinbek/Hamburg, 2000 
Stickland NC, Widdowson EM, Goldspink G (1975): Effects of severe energy and protein deficiencies on the fibres and nuclei in skeletal muscle of pigs. Br J Nutr $\underline{34}, 421-428$

Taafe DR (2006): Sarcopenia: Exercise as a treatment strategy. AFP $\underline{35}$ (3), 130-134

Velleman SG (1999): The Role oft the Extracellular Matrix in Skeletal Muscle Development. Poultry Sci $\underline{78}, 778-784$

Walsh MC, Hunter GR, Livingstone MB (2006): Sarcopenia in premenopausal women with osteopenia, osteoporosis and normal bone mineral density. Osteoporosis Int $\underline{17}, 61-67$

Weber KT, Janicki JS, Shroff SG, Pick R, Chen RM, Bashey RI (1988): Collagen Remodeling of the Pressure-Overloaded, Hypertrophied Nonhuman Primate Myocardium. JAHA $\underline{62}$, 757765

Windler E: Östrogene zur kardiovaskulären Prävention der Frau. Journal für Menopause, Gablitz 2000, 13-15

Wuttke W, Seidlová-Wuttke D, Gorkow C (2003): The Cimicifuga preparation BNO 1055 vs. Conjugated estrogens in a double-blind placebo-controlled study: effects on menopause symptoms and bone markers. EMAS $\underline{44}(1), 67-77$

Wuttke W, Gorkow C, Seidlová-Wuttke D (2006): Effects of black cohosh (Cimicifuga racemosa) on bone turnover, vaginal mucosa, and various blood parameters in postmenopausal women: a double-blind, placebo-controlled, and conjugated estrogenscontrolled study. Menopause, 84

Würfel W (2010): Spektrum der Ovarialfunktion im Klimakterium: Praktische Bedeutung für Endokrinologie und Reproduktionsmedizin. Journal für Gynäkologische Endokrinologie 20(4), 6-11

Xu Y, Arenas IA, Armstrong SJ, Davitge ST (2003): Estrogen modulation of left ventricular remodeling in the aged heart. Cardiovasc Res $\underline{57}(2), 388-394$

Zhao H, Tian Z, Hao J, Chen B (2005): Extragonadal aromatization increases with time after ovariectomy in rats. RB\&E $\underline{3}, 6-8$ 


\section{Tabellenverzeichnis}

Tabelle Thema Seite

Tab. 2.1 Verschiedene Futtergruppen mit berechneten Futterbeimengungen

21

Tab.2.2 Paraffineinbettung: Konzentrationen der Lösungen mit jeweiligen 51 Einwirkzeiten

Tab. 2.3 HE-Färbung

Tab. 2.4 Van-Gieson-Färbung in Kombination mit der Resorcinfuchsinfärbung 55 nach Weigert

Tab. 3.1 Substanzaufnahme der Futtergruppen

Tab. 4.1 Vergleich der gesamten Ergebnisse der Versuche der Herz- und 46 Skelettmuskultur 


\section{$9 \quad$ Abbildungsverzeichnis}

$\begin{array}{lll}\text { Abbildung Thema Seite } & \text { S }\end{array}$

Abb. 1.1 Ansicht der Pflanze CR, deren Wurzelstock Verwendung findet

Abb. 1.2 CR Subfraktionen: Komplementierende Analytik zu C001/S/1-2 17 und $\mathrm{C} 001 / \mathrm{R} / 1-3$

Abb. 2.1 Tierexperimenteller Zeitverlauf

Abb. 2.2 Gewinnung der Präparate

Abb. 2.3 Skelettmuskelfaserflächenmessung

Abb. 2.4 Kardiomyozytenflächenmessung

Abb. 2.5 Querschnitt Skelettmuskulatur

Abb. 2.6 EZM- und Skelettmuskulaturflächenmessung

Abb. 2.7 Querschnitt Herzmuskulatur

Abb. 2.8 EZM- und Herzmuskulaturflächenmessung

Abb. 3.1 Der Effekt von EB, der aus CR extrahierten Saponin- und 30 Restfraktion, und deren Subfraktionen (28 Tage per Futter bei ovx Ratte) auf den Futterverbrauch im Versuch

Abb. 3.2 Der Effekt von EB, der aus CR extrahierten Saponin- und Restfraktion und deren Subfraktionen (28 Tage per Futter bei ovx Ratte) auf die Gewichtszunahme im Versuch 
Abb. 3.3 Der Effekt von EB, der aus CR extrahierten Saponinfraktion

und ihren Subfraktionen auf die Skelettmuskelfaserfläche

Abb. 3.4 Der Effekt von EB, der aus CR extrahierten Restfraktion

und ihren Subfraktionen auf die Skelettmuskelfaserfläche

Abb. 3.5 Der Effekt von EB, der aus CR extrahierten Saponinfraktion

und ihren Subfraktionen auf die Kardiomyozytenfläche

Abb. 3.6 Der Effekt von EB, der aus CR extrahierten Restfraktion

und ihren Subfraktionen auf die Kardiomyozytenfläche

Abb. 3.7 Der Effekt von EB, der aus CR extrahierten Saponinfraktion

und ihren Subfraktionen auf den Anteil an elastischen Fasern

bezogen auf die Skelettmuskelfaserfläche

Abb. 3.8 Der Effekt von EB, der aus CR extrahierten Restfraktion und ihren Subfraktionen auf den Anteil an elastischen Fasern bezogen auf die Skelettmuskelfaserfläche

Abb. 3.9 Der Effekt von EB, der aus CR extrahierten Saponinfraktion und ihren Subfraktionen auf den Anteil an elastischen Fasern bezogen auf die Kardiomyozytenfläche

Abb. 3.10 Der Effekt von EB, der aus $C R$ extrahierten Restfraktion und ihren Subfraktionen auf den Anteil an elastischen Fasern bezogen auf die Kardiomyozytenfläche 


\section{Danksagung}

Besonders herzlich bedanken möchte ich mich bei Frau PD Dr. med. D. Seidlová-Wuttke und Herrn Prof. Dr. med. W. Wuttke, die mir das wissenschaftliche und experimentelle Arbeiten in der Abteilung ermöglicht haben. Große Dankbarkeit empfinde ich darüber hinaus für die umfassende und herzliche Betreuung durch Frau PD Dr. med. D. Seidlová-Wuttke. Mein Dank gilt zudem den medizinisch-technischen Assistentinnen der Abteilung, die mir bei der Durchführung der Experimente behilflich waren. 


\section{Lebenslauf}

Am 6. September 1987 wurde ich, Nina-Antonia Striebe als Tochter des Zahnarztes Dr. med. dent. Michael Striebe und seiner Ehefrau, der Zahnmedizinischen Fachhelferin Susanne Striebe in Hannover geboren.

Zwischen 1994 und 1998 besuchte ich die Grundschule Hemmingen und daran anschließend von 1998 bis 2000 die Orientierungsstufe der Carl-Friedrich-GaußSchule. Darauf folgend wechselte ich auf die Humboldtschule Hannover und absolvierte dort im Sommer 2007 mein Abitur.

Im selben Jahr nahm ich das Medizinstudium an der Georg-August-Universität Göttingen auf.

Von März 2011 bis Oktober 2014 habe ich diese vorliegende Dissertation im Rahmen der ehemaligen Abteilung für klinische und experimentelle Endokrinologie der Universität Göttingen angefertigt.

Das Medizinstudium habe ich mit dem Zweiten Abschnitt der Ärztlichen Prüfung im November 2013 abgeschlossen.

Seit April 2014 befinde ich mich in der Facharztausbildung zur Augenärztin in der Augenheilkunde der Universitätsmedizin Göttingen.

Göttingen den, 14.10.14 Nina-Antonia Striebe 